\title{
Quantifying upper limb motor impairment in people with Parkinson's disease: A physiological profiling approach
}

\author{
Lewis A Ingram ${ }^{\text {Corresp., } 1,2 \text {, }}$,incent K Carroll ${ }^{3,4}$, Annie A Butler ${ }^{1,2}$, Matthew A Brodie ${ }^{1,2}$, Simon C Gandevia ${ }^{1,2}$, \\ Stephen R Lord \\ ${ }^{1}$ Neuroscience Research Australia, Sydney, New South Wales, Australia \\ 2 University of New South Wales, Sydney, New South Wales, Australia \\ 3 NSW Health, Mid North Coast Local Health District, Coffs Harbour, New South Wales, Australia \\ 4 Parkinson's NSW, Sydney, New South Wales, Australia \\ Corresponding Authors: Lewis A Ingram, Stephen R Lord \\ Email address: I.ingram@neura.edu.au, s.lord@neura.edu.au
}

Background: Upper limb motor impairments, such as slowness of movement and difficulties executing sequential tasks, are common in people with Parkinson's disease (PD).

Objective: To evaluate the validity of the upper limb Physiological Profile Assessment (PPA) as a standard clinical assessment battery in people with PD, by determining whether the tests, which encompass muscle strength, dexterity, arm stability, position sense, skin sensation and bimanual coordination can (a) distinguish people with PD from healthy controls, (b) detect differences in upper limb test domains between "off" and "on" anti-Parkinson medication states and (c) correlate with a validated measure of upper limb function.

Methods: 34 participants with PD and 68 healthy controls completed the upper limb PPA tests within a single session.

Results: People with PD exhibited impaired performance across most test domains. Based on validity, reliability and feasibility, six tests (handgrip strength, finger-press reaction time, 9-hole peg test, bimanual pole test, arm stability, and shirt buttoning) were identified as key tests for the assessment of upper limb function in people with PD.

Conclusions: The upper limb PPA provides a valid, quick and simple means of quantifying specific upper limb impairments in people with PD. These findings indicate clinical assessments should prioritise tests of muscle strength, unilateral movement and dexterity, bimanual coordination, arm stability and functional tasks in people with PD as these domains are the most commonly and significantly impaired. 


\section{Quantifying upper limb motor impairment in people with Parkinson's disease: A physiological profiling approach}

Lewis A Ingram ${ }^{1,2}$, Vincent K Carroll ${ }^{3,4}$, Annie A Butler ${ }^{1,2}$, Matthew A Brodie ${ }^{1,2}$, Simon C Gandevia $^{1,2}$, Stephen R Lord ${ }^{1,2, *}$

${ }^{1}$ Neuroscience Research Australia, Sydney, New South Wales, Australia ${ }^{2}$ University of New South Wales, Sydney, New South Wales, Australia ${ }^{3}$ NSW Health, Mid North Coast Local Health District, New South Wales, Australia 4Parkinson's New South Wales, New South Wales, Australia

Corresponding author:

Stephen $\operatorname{Lord}^{1,2}$

Neuroscience Research Australia (NeuRA)

Margarete Ainsworth Building, Barker St,

Randwick, New South Wales, 2031

Phone: +61293991061

1 Email: s.lord@neura.edu.au

2 


\section{Abstract}

4 Background: Upper limb motor impairments, such as slowness of movement and difficulties

5 executing sequential tasks, are common in people with Parkinson's disease (PD).

6 Objective: To evaluate the validity of the upper limb Physiological Profile Assessment (PPA) as 7 a standard clinical assessment battery in people with PD, by determining whether the tests, which 8 encompass muscle strength, dexterity, arm stability, position sense, skin sensation and bimanual 9 coordination can (a) distinguish people with PD from healthy controls, (b) detect differences in 10 upper limb test domains between "off” and "on" anti-Parkinson medication states and (c)

11 correlate with a validated measure of upper limb function.

12 Methods: 34 participants with PD and 68 healthy controls completed the upper limb PPA tests 13 within a single session.

14 Results: People with PD exhibited impaired performance across most test domains. Based on 15 validity, reliability and feasibility, six tests (handgrip strength, finger-press reaction time, 9-hole 16 peg test, bimanual pole test, arm stability, and shirt buttoning) were identified as key tests for the 17 assessment of upper limb function in people with PD.

18 Conclusions: The upper limb PPA provides a valid, quick and simple means of quantifying specific upper limb impairments in people with PD. These findings indicate clinical assessments should prioritise tests of muscle strength, unilateral movement and dexterity, bimanual coordination, arm stability and functional tasks in people with PD as these domains are the most commonly and significantly impaired.

Key words: Parkinson Disease, Upper Extremity, Movement Disorders, Levodopa, Hypokinesia, Tremor. 


\section{Introduction}

28 Parkinson's disease (PD) is a progressive, degenerative neurological condition characterised by

29 rigidity, slowness of movement, resting tremor and postural instability $[1,2]$, the degree to which

30

31

32

34

35

36

37 varies considerably from patient to patient and changes over time $[2,3]$. These motor impairments result from the destruction of neurons in the substantia nigra, a region of the midbrain responsible for the production of dopamine [4-6], a neurotransmitter that is critical for the facilitation of voluntary movement [7]. This loss in dopaminergic cells is thought to inhibit the motor thalamic nuclei, resulting in decreased excitation at the cortical level [8-11]. In the upper extremities, these pathological changes can manifest as difficulties in reaching, grasping and manipulating objects with sufficient speed and dexterity [12]. Such upper limb impairments commonly lead to difficulties with eating, drinking and self-care and can restrict participation in work, recreation and social activities $[13,14]$.

While clinical guidelines are provided for the assessment of balance and gait in people with PD, guidelines for clinical assessments of upper limb functioning across multiple domains are comparatively less developed [15,16]. Indeed, Proud et al. [17] highlighted in their recent systematic review the lack of high-quality studies supporting the validity and responsiveness of the many clinical tests currently used in the assessment of upper limb function in people with PD. As a consequence, clinicians may rely on non-standardised or generic tests of manual dexterity, along with assessment tools designed for other clinical populations [18]. Implementation of a standardised approach to quantify upper limb impairment and treatment effects would help to promote evidence-based practice for the health care needs of people with PD $[17,19]$.

The upper limb Physiological Profile Assessment (PPA) provides quantitative measures of key physiological domains essential for upper limb function, including muscle strength, dexterity, arm stability, position sense, skin sensation and bimanual coordination [20]. Modelled on the original PPA [21,22] as a means of quantifying fall risk in older people and neurological populations, the upper limb PPA is designed to be clinically valid, simple and quick to administer, and capable of generating quantitative scores of key domains required for adequate upper limb function. Therefore, the upper limb PPA offers an 'impairment-based' profile to complement medically-based diagnoses. Given the inter-individual variability in both the motor 
57 symptoms expressed and the relative magnitude of each, the upper limb PPA offers a means of

58 individualising treatment and rehabilitation strategies based on a patient's specific impairments.

59 An additional consideration for the assessment of physical functioning in people with PD is the

60 timing of the assessment and medication intake. In levodopa-treated patients, the 'on-off'

61 phenomenon - characterised by a decline of motor function or, in more severe cases, sudden and

62 unpredictable motor fluctuations, commonly occurs during the 'off' phase towards the end-of-

63 dose [23]. To assess the extent of this change, assessment of upper limb function is required

64 during both the 'on' state - about 30 minutes after the administration of levodopa, as well during

65 the 'wearing off' period approximately 45-60 minutes prior to the next scheduled dose.

66 The aims of this validation study were to: (a) compare upper limb PPA test scores in people with

67 PD to that of age- and gender-matched controls without PD, (b) assess associations between

68 performance in each test and age, disease duration, disease severity and upper limb function, (c)

69 compare test performance between the 'on' and 'off' states in people with PD, (d) to identify key

70 tests from the upper limb PPA for assessing upper limb function in people with PD and e)

71 present PD group and individual upper limb physiological profiles based on established

72 normative values for each test. We hypothesised: people with PD would demonstrate impaired

73 performance across most upper limb PPA tests when compared to age- and gender-matched

74 controls without PD, and within the PD group most upper limb PPA tests would discriminate

75 between medication states with test performances associated with disease duration, disease

76 severity and upper limb function.

77

\section{Methods}

\section{Participants}

80 Thirty-four people with Parkinson's disease participated in the study (47 to 87 years, 22 males

81 and 12 females). All participants provided written and verbal consent prior to participation.

82 Participants were recruited from three Parkinson's New South Wales support groups located on

83 the Mid North Coast, New South Wales, Australia. For inclusion, participants had to be aged 18

84 years or older, and have had received a clinical diagnosis of PD by a neurologist with a score of

85 1-4 on the Hoehn and Yahr (HY) scale. Prospective participants were excluded if they could not 
86 provide verbal or written consent, were unable to follow test instructions, or have any concurrent

87 musculoskeletal and/neurological condition that could affect test performance. Testing took

88 place in March 2019 and was conducted at a testing facility or within participants' homes.

89 For each participant with PD, two age- and gender-matched controls without PD were randomly 90 selected from the database of a research study previously conducted at Neuroscience Research 91 Australia [20]. Ethical approval was granted by the Human Research Ethics Committee,

92 University of New South Wales (HC 15607). All assessments were conducted in accordance 93 with the Declaration of Helsinki (2008).

\section{Procedure}

96

Each PD participant was tested twice, i.e. in their 'on' and 'off' medication states. The order in which this occurred was determined by participant convenience and logistics. At the beginning of the initial assessment, participants completed the Disabilities of the Arm, Shoulder and Hand (DASH) questionnaire [24]. The DASH is a 30-item questionnaire used to measure upperextremity function [25]. Participants are scored on a 100-point scale, with higher values indicating increased levels of self-reported upper limb impairment. DASH scores were not calculated until after the completion of testing. Visual acuity was screened using a Logarithmic Visual Acuity Chart (SLOAN Two Sided ETDRS Format Near Point Test) calibrated for testing at $40 \mathrm{~cm}$ (Precision Vision, USA). This was to ensure that each participant had satisfactory vision to complete the subsequent tests [26]. Visual aids were permitted where necessary. Participants then completed the upper limb tests (see below). A single examiner assessed all participants with each test session taking approximately 60 minutes.

The upper limb PPA consists of 13 tests (with a total of 16 test measures) classified into the physiological domains of muscle strength, unilateral movement and dexterity, position sense, skin sensation, bimanual coordination, arm stability and functional tasks. The tests have been shown to be sensitive in detecting motor impairments in people with compromised upper limb function from the general population. Age and gender normative scores are available for each test [20]. Each of the 13 tests are outlined briefly below, and have been described in detail previously [20]. 


\section{Measurements}

117 Muscle strength was assessed at the elbow (isometric elbow flexion strength) and the hand

118 (handgrip strength). Isometric elbow flexion strength was assessed using a digital hanging

119 scale anchored to a portable wooden platform situated beneath the chair while participants were

120 seated with the elbow joint flexed at $90^{\circ}$ and forearm supinated. Handgrip strength was

121 assessed with Jamar+ Digital Dynamometer. The best of three trials (measured in kilograms) was

122 recorded as the test score. Unilateral movement and dexterity were assessed via finger-press

123 reaction time, finger tapping, 9-hole peg test, and the loop \& wire test. Finger-press reaction

124 time was assessed in milliseconds using a modified computer mouse containing a light stimulus

125 embedded in the left button, which participants responded to by pressing the right button. The

126 number of times participants could tap their index finger on a touch pad over a 10-second period

127 provided the test score for the finger tapping test. The 9-hole peg test (9-HPT) was measured

128 (in seconds) as the time taken for the participant to pick up each peg individually, place them

129 into each of the holes, and then return them to the molded dish [27,28]. The average number of

130 times the participant touched the copper wire maze on each of the two trials of the loop \& wire

131 test was recorded as the test score. Position sense was measured using an elbow matching test,

132 where differences (in degrees) in aligning the index fingers was recorded using a clear acrylic

133 sheet marked with a protractor that was vertically aligned to the participants midline, with the

134 average error of 5 trials recorded as the test score. Tactile sensitivity, two-point discrimination

135 and two-line discrimination were used to quantify skin sensation. For tactile sensitivity, von-

136 Frey filaments were used to assess perceptual thresholds (measured in grams) to cutaneous

137 stimuli at the hypothenar eminence. Static two-point discrimination was measured (in $\mathrm{mm}$ )

138 using a small- (2-8 $\mathrm{mm})$ and large-interval $(9-20 \mathrm{~mm})$ Mackinnon-Dellon Disk-Criminator

139 applied along the mediolateral axis of the distal pad of the index finger. Two-line

140 discrimination measured the smallest distance (in $\mathrm{mm}$ ) that participants could accurately detect

141 between two lines of $0.6 \mathrm{~mm}$ diameter as they progressively separated over a distance of 580

$142 \mathrm{~mm}$. Bimanual coordination was tested using the bimanual pole test where participants moved a

143 screw embedded within a modified swivel stick back and forth through a maze as fast as possible

144 by flexing and extending the wrists in a coordinated manner (measured in seconds). Arm 
145 stability was measured as the total path (in degrees) that the participants' wrist moved as they sat

146 with their outstretched arm held perpendicular to the floor over a period of 30 seconds.

147 Participants completed four conditions (unweighted eyes open/closed; weighted eyes

148 open/closed). The shirt task was used as a measure of functional performance. Here, participants

149 were timed as they put on a long sleeve shirt and did up all six buttons (measured in seconds).

150 With the exception of handgrip strength [29] and the 9-hole peg test [30,31], none of the upper

151 limb PPA tests have previously been validated in the PD population. However, measures of

152 finger tapping speed and amplitude, tremor and bimanual coordination are all included in the

153 MDS-UPDRS [32], underscoring their importance in the overall assessment of upper limb

154 function in people with PD. Participants performed each unilateral test with their dominant hand,

155 and were seated for all tests with the exception of the shirt task. The number of trials for each test

156 were based on standard protocols for previously validated tests, and restricted to one or a few

157 trials for some of the novel test to facilitate quick administration and preclude leaning effects.

158

159 Data and statistical analysis

160 Continuous data are reported as mean $\pm \mathrm{SD}$ or, if normality assumptions were violated, medians

161 (interquartile range [IQR]). Independent t-tests and Mann-Whitney tests were used to contrast

162 performances in each of the upper limb PPA tests between the PD group and the age- and

163 gender-matched healthy controls. Correlations between test performance, age, duration of PD,

164 HY scale and DASH scores were assessed using Pearson's $r$ and Spearman's rho, and were

165 interpreted as follows: $<0.3$ - negligible, 0.3-0.5 - small, 0.5-0.7 - moderate, and >0.7 - strong.

166 Differences in test performance between the 'off' and 'on' medication states in the PD group

167 were analysed using paired t-tests and Wilcoxon matched pairs tests. Finally, to highlight the

168 degree to which test performances are impaired, test scores for the PD group during the 'off' and

169 'on' states were converted to standardised (z) scores based on data from a reference cohort of

170 people without PD [20]. By doing so, a score of zero indicates average performance for healthy

171 controls aged 50 years and over and each unit represents one standard deviation: positive and

172 negative scores indicate above and below average performances respectively. The reference

173 cohort was used to compile the profiles, as it is common to our proposed companion papers

174 addressing other neurological conditions such as stroke, and thus provides a robust way to 
175 contrast upper limb impairments among clinical groups. For this analysis, variables were $\log _{10}$

176 transformed if normality assumptions were violated.

177 For position sense, two-line discrimination and the shirt task, no scores were available for one, three

178 and four participants, respectively, who could not complete the task. With the exception of the two-

179 line discrimination test, these participants were assigned a maximum score, which was calculated as

180 the mean + 3SD's from data from 124 participants with neurological disorders: 34 participants with

181 PD (the current sample), 50 stroke participants and 40 participants with multiple sclerosis. Maximum

182 scores for these tests were calculated as $13.5^{\circ}$ and 300 seconds for position sense and the shirt task,

183 respectively. For the two-line discrimination test, these participants were assigned the maximum

184 score available for this test: $4 \mathrm{~mm}$. Furthermore, a small number of participants registered scores

185 that were beyond those maximum scores that were calculated from the same database of 124

186 participants with neurological disorders (i.e. the mean + 3SD's for each test). These included

187 finger-press reaction time $(\mathrm{n}=1$, off state), 9-hole peg test $(\mathrm{n}=1$, on state), arm stability eyes

188 closed ( $n=1$, off state; $n=1$, on state), arm stability weight eyes open ( $n=1$, off state), arm

189 stability weight eyes closed $(n=2$, off state), and the shirt task $(n=1$, off state). In each of these

190 cases, the participant was assigned the maximum score for each of these tests, i.e. $500 \mathrm{~ms}, 180 \mathrm{~s}$,

$191400^{\circ}$ and $300 \mathrm{~s}$, respectively.

192 All statistical analyses were performed using GraphPad Prism 7 software and Estimation

193 Statistics Beta $[33,34]$ with the level of significance set at $p<0.05$. All data are presented in

194 Supplementary File 1.

195

196 Results

197 Participant characteristics

198 Table 1 shows demographic, visual acuity, disease duration, PD severity (HY scale), and self-

199 reported upper limb function measures (DASH scores) for the PD group $(n=34)$. The mean age

200 was 68.6 years (range $=47-87)$ with women making up 35\% $(\mathrm{n}=12)$ of the sample. All but five

201 participants identified as right-hand dominant. The mean $\log$ MAR score was 0.26

202 (corresponding to a Snellen eye chart score of 6/12 - adequate for all tests in the assessment

203 battery). Twenty-seven participants performed the initial round of testing during their 'off'

Peer) reviewing PDF | (2020:04:47587:2:0:NEW 16 Dec 2020) 
204 medication phase, between the hours of 0800 and 1000 with no PD medication taken after

205 retiring to bed the night before. The median time since diagnosis was 5.0 years (IQR $=3.0-10.0)$

206 and the mean HY scale score was 2.7 (range = 1-4), suggestive of bilateral symptoms with

207 impaired postural reflexes but physically independent. The mean DASH score of 36 out of 100

208 exceeds the threshold of 15, which indicates self-reported upper limb function [35].

209 Demographic, visual acuity and DASH scores for the age- and gender-matched controls are also 210 shown in Table $1(\mathrm{n}=68)$. Both the mean $\log$ MAR $(0.14)$ and DASH scores (6.6) were lower

211 than in the PD group, indicating better visual acuity and lower levels of self-reported upper limb 212 function, respectively.

213 For the reference cohort of people without PD $(n=176)$, the mean age was 70.1 years (range $=$ 214 50-96) with a 53:47 ratio of females to males (Table 1). Visual acuity and DASH scores were 215 comparable to that of the age- and gender-matched control group.

216

\section{Comparison with age- and gender-matched controls without PD}

218 During the 'off' state, the PD group performed worse than the healthy control group in all tests 219 with the exception of isometric elbow flexion strength, two-point discrimination and two-line 220 discrimination (Table 2 and Figures 1-4). The same pattern of associations was evident in the

221 'on' state, with the exception that scores in bimanual pole test did not differ between the PD and 222 healthy control participants.

223

224

Comparison with normative values

225 Figure 5 presents test results as standardised (z) scores for the PD group during the 'off' and 'on' 226 states referenced to the reference cohort without PD [20]. These profiles indicate that compared 227 to healthy controls, the PD group was most impaired in the shirt task (z scores $<-2$ ), moderately 228 impaired with respect to isometric elbow flexion strength (females, 'off' state only), finger-press 229 reaction time, 9-hole peg test, loop and wire test ('off' state only), and all four conditions of the 230 arm stability test (except for the two eyes open conditions during the 'on' state) (z scores 231 between -1 and -2 ) and relatively less impaired with respect to the remaining tests (z scores $>-$ 
232 1). Figure 6 highlights the inter-individual variability in the clinical presentation of upper limb

233 motor impairments among four PD participants by contrasting their individual performance

234 profiles, each derived from the reference cohort normative values.

235

Test performance in relation to age, $P D$ duration, disease severity and

237 upper limb function

238 In the 'off' state, poorer performance in the handgrip strength, two-point discrimination and

239 bimanual pole test demonstrated small associations with increased age, while during the 'on'

240 state, age showed small and moderate associations with poorer performance in both measures of

241 muscle strength and the 9-hole peg test (Table 3 and Figures 7 and 8). Finger-press reaction time

242 and tactile sensitivity were the only tests associated with time since PD diagnosis during the 'on'

243 medication state, with the direction of the relationship indicating worse performance with longer

244 disease duration. The strengths of these associations were small $(0.3-0.5)$. No tests were

245 significantly associated with disease duration during the 'off' state.

246 During the 'off' state, poorer performance in the 9-hole peg test, loop and wire, and bimanual

247 pole test demonstrated small associations with increased PD severity, as measured by the HY

248 scale, while finger-press reaction time and shirt task performance were moderately associated

249 with increased HY scale scores. During the 'on' state, finger tapping, loop and wire, arm stability

250 (eyes closed, weight eyes open), and shirt task performance demonstrated small associations with

251 the HY scale, while performance in finger-tapping and 9-hole peg test were moderately

252 associated with the HY scale.

253 During the 'off' state, higher levels of self-reported deficits in upper limb function, as measured

254 by the DASH questionnaire, demonstrated small associations with reduced performance in

255 finger-press reaction time, 9-hole peg test, bimanual pole test, and the shirt task, while both tests

256 of muscle strength and two-point discrimination were moderately associated with the DASH

257 questionnaire scores. Lastly, poorer performance during the 'on' state in the 9-hole peg test, and

258 bimanual pole test, arm stability (eyes closed), and the shirt task showed small associations with

259 higher DASH questionnaire scores, while both tests of muscle strength and finger-press reaction

260 time were moderately associated with the DASH. 


\section{Comparison of test scores between the 'on' and 'off' states}

263 Mean $( \pm \mathrm{SD})$ and median (IQR) test scores between the 'on' and 'off' medication states are

264 presented in Table 4. Differences in performance were observed for isometric elbow flexion

265 strength, 9-hole peg test, position sense, bimanual pole test and the two weighted conditions of

266 the arm stability test. In each case, participants performed better during the 'on' state. There was

267 no difference in performance between medication states for the remaining tests.

268

269

Key tests for assessing upper limb function in people with PD

270 Table 5 presents a weighting system based on validity, reliability and feasibility for determining

271 optimal tests of upper limb function in people with PD. Modelled on a scale devised to identify

272 useful mobility tests for predicting falls in older people [36], equal weights were allocated to (i)

273 ability to differentiate between people with PD during their 'on' state and healthy controls, (ii)

274 significant correlations with self-reported upper limb function (DASH scores), (ii) ability to

275 detect differences between 'off'/'on' medication states, (iv) feasibility with respect to test

276 administration and (v) demonstrated reliability across the adult lifespan [20]. As indicated in

277 Table 5, the handgrip strength, finger-press reaction time, 9-hole peg, bimanual pole, and arm

278 stability tests along with the functional shirt task were identified as key tests.

279

\section{Discussion}

281 This study compared performance in a broad range of upper limb function tests between people 282 with PD both with a healthy age- and gender-matched control group, as well as with normative 283 values taken from people aged 50 years and over in the general population. These comparisons 284 revealed that people with PD performed significantly worse across all domains with the 285 exception of proximal muscle strength and tactile discrimination. Specifically, deficits were most 286 apparent in fine motor control and dexterity, arm stability and functional tasks. When considered 287 alongside correlations with the DASH questionnaire and test-retest reliability, these findings 
288 suggest that the handgrip strength, finger-press reaction time, 9-hole peg test, bimanual pole test, 289 arm stability and the shirt task are key tests for assessing upper limb function in people with PD.

290 The results of the current study are largely consistent with that of previous research reporting 291 impaired performance in single upper limb domains in people with PD when compared to the 292 general population. Specifically, people with PD have deficits in measures of handgrip strength 293 [29,37-41], fine motor control (9-hole peg test) [30,31], tactile sensitivity (when tested at the 294 dorsum of the hand) [42], simple reaction time [43], finger-tapping speed [44-52], position sense 295 (during both active and passive elbow-matching tasks [53], and movement detection thresholds 296 [54,55]), bimanual coordination (slower, less accurate and greater inter-trial variability) [56-58] 297 and arm stability [59,60].

298 Comparisons of proximal upper limb strength between people with PD and healthy controls have 299 been inconsistent, due in part to differences in the muscles tested (i.e. elbow extensors vs. 300 flexors) and the parameters used to quantify strength. Specifically, people with PD demonstrate 301 weakness in isometric elbow extension - not flexion [61], and take longer to reach their peak 302 torque during isometric elbow flexion and demonstrate more irregularities in their force-time 303 profiles $[62,63]$. Our finding that tactile spatial acuity did not differ between PD and healthy 304 control participants contrasts with a study by Schneider et al [64], who reported a significant 305 mean two-discrimination score of $4.6 \mathrm{~mm}$ at the index finger in a sample of 15 people with PD 306 of comparable severity and gender distribution to that of recruited for the current study. The 307 reason for these divergent findings is unclear, although may relate to differences in disease 308 duration, not reported in the Schneider et al study [64].

309 Our comparisons in performance between the 'on' and 'off' medication states contrast with some 310 previous research. For example, Corcos et al. [61] reported a 34\% reduction in isometric elbow 311 extension strength when comparing performance between 'on' and 'off' states, but no difference 312 in elbow flexion strength. While this latter finding conflicts with ours, it is acknowledged the 313 magnitude of difference in elbow flexion strength between medication states in our study was 314 small $(1 \mathrm{~kg})$, and therefore of uncertain clinical relevance.

315 Other discrepancies are evident for position sense, matching tasks and reaction time.

316 O'Suilleabhain et al. [65] reported that people with PD performed worse during their 'on' state 317 during an elbow matching task which they attributed to levodopa-induced dyskinesias. The 
318 discrepancy between studies could be attributed to the O'Suilleabhain et al. study using a passive 319 positioning test as opposed to the active positioning used in the current study, which would have 320 potentially eliminated the role of central motor commands contributing to position sense at the

321 elbow (for review, see [66,67]). While Quincy \& Brown [68] reported no improvement in

322 bimanual task performance during the 'on' medication state, comparisons with the current study

323 are limited due to differences in the test performed and the parameters used to quantify

324 performance. Finally, differences in performances between medication states for measures of

325 simple reaction time are equivocal [43,69-74], with more complex tests (i.e. choice reaction

326 time) appearing more sensitive in discriminating between the 'on' and 'off' states.

327 The standardised scores for both the 'on' and 'off' states indicate the extent to which people with 328 PD are impaired in relation to normative values taken from people without PD. The profiles 329 scores indicate the PD participants performed markedly worse than the healthy controls in the 330 reaction time, 9-hole peg test, loop and wire and arm stability tests (z-scores $<-1)$ while being 331 relatively less affected in terms of tactile sensitivity and muscle strength (with the exception of 332 proximal strength in females during the 'off' state) (Figure 5). These deficits are consistent with 333 the cardinal symptoms of PD including bradykinesia, rigidity and tremor. In contrast, the 334 relatively small finger tapping decrement, while consistent with a previous study by Haaxma et 335 al. [45], was unexpected given this is an accepted marker of bradykinesia. Most notably, 336 performance in the shirt task was distinctly compromised in people with PD in terms of time 337 taken to complete the sequential task (z-scores $<-2$ ), which appears to reflect summed 338 impairments in the physiological domains of dexterity, position sense, tactile sensitivity and 339 bimanual coordination required for this functional task [20]. Indeed, people with PD have 340 impaired performance in the specific tests that singly quantify each of these domains both within 341 the current study and those previously reported - specifically, the 9-hole peg test [30,31], elbow 342 position-matching tasks [53,65], von Frey filaments applied to the dorsum of the hand [42], and 343 both anti-phase [56-58] and in-phase bimanual tasks [57].

344 While performance in some tests correlated with the severity of PD symptoms - as measured by 345 the HY scale, small to moderate associations with test performance were more consistent with a 346 validated measure of upper limb function - the DASH questionnaire. This emphasises the 347 importance of individual upper limb PPA tests for quantifying upper limb impairment and 348 performance in functional tasks on the one hand, and the limited value of the HY scale in 
349 documenting upper limb disability in people with PD on the other [75]. This is not surprising 350 given the HY scale's scoring criteria's emphasis towards impairments in postural stability and 351 functional limitations in gait, especially towards the higher end of the scale. Despite being 352 designed specifically for people with musculoskeletal shoulder disorders, the DASH appears 353 sensitive in identifying upper limb impairments, activity limitations and participation restrictions 354 in people with PD when compared to healthy control counterparts. An adapted version of the 355 DASH questionnaire designed specifically for people with PD that incorporates the motor 356 fluctuations commonly observed between the on/off states and quantifies the impact of key 357 symptoms, such as tremor and bradykinesia, on everyday activities may refine the scale and 358 provide further insight into the implications of PD from an activity and participation perspective $359[17]$.

360 Finally, in their 'on' compared with their 'off' medication state, the PD participants performed 361 significantly better in tests of proximal muscle strength, finger dexterity, position sense, 362 bimanual coordination and weighted arm stability. This suggests these tests would have value in 363 distinguishing between those who do and do not respond to the administration of levodopa in 364 clinical practice. Indeed, a computerised 25-peg insertion test - analogous to the 9-hole peg test, 365 was sensitive to levodopa status in people with PD [76]. Importantly, this may be relevant to 366 people with relatively early disease - such as the current sample (median time since diagnosis $=$ 3675.0 years), as people with PD generally first experience levodopa-related dyskinesias and motor 368 fluctuations approximately 5-10 years after initiating levodopa treatment [23]. The lack of 369 change in performance between 'off' and 'on' states for the shirt task is surprising. Perhaps 370 compensation is most profound for complicated multimodal tasks.

371 Nevertheless, further studies with larger sample sizes are required to confirm the discriminant 372 validity of the aforementioned tests in differentiating between medication states in the PD 373 population. Furthermore, it must be cautioned that despite the statistical differences between 374 medication states, the actual difference in scores between 'off' and 'on' states does indeed 375 appear small in most cases, bringing the clinical significance of such findings into question. This 376 is particularly true for position sense given its somewhat large coefficient of variation (CV) of 377 measurement error when assessed in a healthy population [20]. 


\section{Clinical implications}

380 The study reveals the extent to which people with PD are impaired across the physiological domains necessary for adequate upper limb function: muscle strength, reaction time, fine motor

382

383

384

385

386

387

388

389

390

391

392

393

394

395

396

397

398

399

400

401

402

403

404

405

406

407 control and dexterity, bimanual coordination, arm stability and functional tasks. Furthermore, as most of the tests demonstrate good criterion validity against the DASH questionnaire, and are simple and quick to administer, they constitute an excellent assessment battery for assessing upper limb for people with PD in the clinical setting. Here, they may play a valuable role in identifying specific motor impairments, monitoring disease progression and evaluating rehabilitation strategies designed to improve upper limb function. A number of the tests discriminate test performance between the "off" and "on" medication states, and offer scope for evaluating the efficacy of drug therapies and additional assessments to identify people with PD who do and do not respond to levodopa. The greatest asset that the upper limb PPA offers alongside the currently available tests is that it enables clinicians to quantify performance across multiple physiological domains necessary for independence of everyday activities with the upper extremities - each of which will be compromised to various degrees between patients with PD $[2,3]$. This will allow the development of a performance profile that identifies the specific deficits (and their magnitude) in each individual, thereby tailoring rehabilitation and treatment to each patient's specific needs.

\section{Strengths and limitations}

Strengths of the study included the comprehensive range of upper limb function tests, the assessments undertaken in both the on and off medication states, and the inclusion of participants across a broad age and PD severity ranges (1-4 on the HY scale). We also acknowledge some limitations. First, the Movement Disorder Society-sponsored revision of the Unified Parkinson's Disease Rating Scale (MDS-UPDRS) was not administered in our PD sample, so we are not able contrast upper limb PPA scores with this established PD severity rating scale. However, our analyses contrasted upper limb PPA performances with PD severity as assessed with the HY scale and it is important to note the upper limb PPA was not designed as an alternative to the MDS-UPDRS scale, but rather a complementary quantitative battery of clinical tests that can 
408 identify specific sensory and motor impairments in individual patients. Second, due to logistical

409 constraints, some participants may not have been in a complete 'off' state for their 'off'

410 assessments, as it was not possible to withhold all PD medication for at least 12 hours in all

411 participants [77]. However, the majority of participants would have met this condition as they

412 withheld their first daily PD medication dose till after their 'off' assessment. Therefore, if

413 anything, our results may underestimate the ability of the upper limb PPA to document the

414 effects of PD medication on upper limb function. For similar practical reasons, the assessor could

415 not be blinded to medication status and the testing session order could not be randomised, and 27

416 of the 34 participants completed the initial session in their 'off' state and the second session in

417 their 'on' state. Consequently, it is possible that learning effects may have influenced the 'on'

418 assessments. This may be particularly the case for the bimanual pole test due to the novel nature

419 of this task. Another limitation is that to minimize participant burden, participants performed the

420 unilateral tests with the dominant hand only. However, given that 30 out of the 34 participants

421 included in the current sample scored 2 or more on the HY scale (indicating bilateral

422 involvement of PD-related symptoms), our results should still largely represent the sensorimotor

423 impairments experienced by people with PD when performing everyday activities with their

424 upper limbs. While we did not screen participants for cognitive impairment prior to participation,

425 all included participants were able to follow the test instructions for each test without difficulty.

426 Finally, although previous studies have reported good test-retest reliability for handgrip strength

427 and the 9-hole peg test in people with PD [39,78] and we have reported acceptable test-rest

428 reliability for all measures in a large sample of people without neurological conditions [20], we

429 did not assess test-retest reliability in the current study sample.

430

\section{Conclusion}

432 In conclusion, the study findings reveal the extent to which people with PD are impaired across

433 many physiological domains necessary for adequate upper limb function: muscle strength,

434 unilateral movement and dexterity, bimanual coordination, arm stability and functional tasks.

435 The upper limb PPA may therefore complement the MDS-UPDRS by providing individual upper

436 limb performance profiles (as indicated in Figure 6) to assist in understanding functional 
437 limitations and informing tailored treatments. As each of the tests that quantify performance in 438 many domains demonstrate good validity when compared to the criterion of the DASH 439 questionnaire, and are simple and quick to administer, they constitute an excellent assessment 440 battery for assessing upper limb function in people with PD in the clinical setting. Here, they 441 may play a role in identifying specific motor impairments, and evaluating pharmaceutical and 442 physical rehabilitation therapies designed to monitor and address disease progression and 443 improve upper limb function. 


\section{References:}

445 1. Kalia LV, Lang AE. Parkinson's disease. Lancet 2015; 386: 896-912.

446 2. Jankovic J. Parkinson's disease: clinical features and diagnosis. J Neurol Neurosurg 447 Psychiatry 2008; 79: 368-376.

448 3. Politis M, Wu K, Molloy S, G Bain P, Chaudhuri KR, Piccini P. Parkinson's disease 449 symptoms: The patient's perspective. Mov Disord 2010; 25: 1646-1651.

450 4. Schneider SA, Obeso JA. Clinical and pathological features of Parkinson's disease. Curr 451 Top Behav Neurosci 2015; 22: 205-220.

452 5. Obeso JA, Marin C, Rodriguez-Oron C, Blesa J, Benitez-Temiño B, Mana-Segovia J, 453

454

455

456

457 Rodríguez M, Olanow CW. The basal ganglia in Parkinson's disease: current concepts and unexplained observations. Ann Neurol 2008; 64: S30-S46.

6. Kordower JH, Olanow CW, Dodiya HB, Chu Y, Beach TG, Adler CH, Halliday GM, Bartus RT. Disease duration and the integrity of the nigrostriatal system in Parkinson's disease. Brain 2013; 136: 2419-2431.

458

459

7. Harrington DL, Haaland KY. Sequencing in Parkinson's disease. Abnormalities in programming and controlling movement. Brain 1991; 114: 99-115.

460

461

8. Burciu RG, Vaillancourt DE. Imaging of motor cortex physiology in Parkinson's disease.

462 Mov Disord 2018; 33: 1688-1699.

9. Broski SM, Hunt CH, Johnson GB, Morreale RF, Low VJ, Peller PJ. Structural and

464

465 functional imaging in parkinsonian syndromes. Radiographics 2014; 34: 1273-1292.

10. Albin RL, Young AB, Penney JB. The functional anatomy of basal ganglia disorders.

467 Trends Neurosci 1989; 12: 366-375. Neurosci 1990; 13: 244-254.

12. Proud EL, Morris ME. Skilled hand dexterity in Parkinson's disease: effects of adding a concurrent task. Arch Phys Med Rehabil 2010; 90: 794-799.

13. Peto V, Jenkinson C, Fitzpatrick R, Greenhall R. The development and validation of a short measure of functioning and well being for individuals with Parkinson's disease. Qual Life Res 1995; 4: 241-248. 
473

474

475

476

477

478

479

480

481

482

483

484

485

486

487

488

489

490

491

492

493

494

495

496

497

498

499

500

501

502

503

14. Morris ME. Movement disorders in people with Parkinson's disease: a model for physical therapy. Phys Ther 2000; 80: 578-597.

15. Aragon A, Ramaswamy B, Ferguson C. The professional's guide to Parkinson's disease. London: Parkinson's Disease Society of the United Kingdom; 2007.

16. Keus SHJ, Hendriks HJ, Bloem BR,Bredero-Cohen AB, de Goede CJT, van Haaren M. Guidelines for physical therapy in patients with Parkinson's disease. Amersfoort (The Netherlands): Association of Physiotherapists in Parkinson's Disease Europe; 2004.

17. Proud EL, Miller KJ, Bilney B, Balachandran S, McGinley JL, Morris ME. Evaluation of measures of upper limb functioning and disability in people with Parkinson disease: a systematic review. Arch Phys Med Rehabil 2015; 96: 540-551.

18. Proud EL, Miller KJ, Martin CL, Morris ME. Upper-limb assessment in people with Parkinson disease: is it a priority for therapists, and which assessment tools are used? Physiother Can 2013; 65: 309-316.

19. Fawcett AL. Principles of assessment and outcome measurements for occupational therapists and physiotherapists: theory, skills and application. Chichester: John Wiley \& Sons Ltd; 2007.

20. Ingram LI, Butler AA, Walsh LD, Brodie MA, Lord SR, Gandevia SC. The upper limb Physiological Profile Assessment: description, reliability, normative values and criterion validity. PLoS ONE 2019; 14: e0218553.

21. Lord SR, Menz HB, Tiedemann A. A physiological profile approach to falls risk assessment and prevention. Phys Ther 2003; 83: 237-252.

22. Lord SR, Delbaere K, Gandevia SC. Use of a physiological profile to document motor impairment in ageing and in clinical groups. J Physiol 2016; 594: 4513-4523.

23. Bhidayasiri R, Truong DD. Motor complications in Parkinson disease: clinical manifestations and management. J Neurol Sci 2008; 266: 204-215.

24. Hudak P, Amadio PC, Bombardier C, Upper Extremity Collaborative Group. Development of an Upper Extremity Outcome Measure: The DASH (Disabilities of the Arm, Shoulder, and Hand). Am J Ind Med 1996; 29: 602-608.

25. Beaton DE, Davis AM, Hudak P, McConnell S. The DASH (Disabilities of the Arm, Shoulder and Hand) outcome measure: What do we know about it now? Br J Hand Ther 2001; 6: 109-118. 
504 26. Lovie-Kitchin JE. Is it time to confine Snellen charts to the annals of history? Ophthalmic $505 \quad$ Physiol Opt 2015; 35: 631-636.

506 27. Kellor M, Frost J, Silberberg N, Cummings R. Hand strength and dexterity. Am J Occup $507 \quad$ Ther 1971; 25: 77-83.

28. Mathiowetz V, Weber K, Kashman N, Volland G. Adult norms for the Nine Hole Peg Test of finger dexterity. OTJR: Occup Particip Health 1985; 5: 24-38. of grip strength with severity and duration of Parkinson's: A cross-sectional study. Neurorehabil Neural Repair 2015; 29: 889-896. test of upper extremity function: average values, test-retest reliability, and factors contributing to performance in people with Parkinson disease. J Neurol Phys Ther 2011; 35: $157-163$.

31. Shah T, Shetty M, Bose M, Mullerpatan R. A study of fine and manual hand dexterity in people with Parkinson's disease. Critical Reviews in Physical and Rehabilitation Medicine 2019; 31: 93-100.

32. Movement Disorder Society Task Force on Rating Scales for Parkinson's Disease. The unified Parkinson's disease rating scale (UPDRS): status and recommendations. Mov Disord 2003; 18: 738-750.

33. Ho J, Tumkaya T, Aryal S, Choi H, Claridge-Chang A. Moving beyond P values: Everyday data analysis with estimation plots. Nat Methods 2019; 16: 565-566.

34. Cumming G, Calin-Jageman R. Introduction to the new statistics: estimation, open science, and beyond. New York: Routledge; 2016.

35. Kennedy CA, Beaton DE, Solway S, McConnell S, Bombardier C. The DASH outcome measure user's manual. 3rd ed. Toronto: Institute for Work \& Health; 2011.

36. Tiedemann A, Shimada H, Sherrington C, Murray S, Lord S. The comparative ability of eight functional mobility tests for predicting falls in community-dwelling older people. Age Ageing 2008; 37: 430-435.

37. Cano-de-la-Cuerda R, Pérez-de-Heredia M, Miangolarra-Page JC, Muñoz-Hellín, Fernández-de-Las-Peñas C. Is there muscular weakness in Parkinson's disease? Am J Phys Med Rehabil 2010; 89: 70-76. 
38. Koller W, Kase S. Muscle strength testing in Parkinson's disease. Eur Neurol 1986; 25:

536 $130-133$. the Handgrip Strength Test in Elderly Subjects With Parkinson Disease. Hand (N Y) 2016; 11: 54-58.

40. Jordan N, Sagar HJ, Cooper JA. A component analysis of the generation and release of isometric force in Parkinson's disease. J Neurol Neurosurg Psychiatry 1992; 55: 572576.

41. Jones GR, Roland KP, Neubauer NA, Jakobi JM. Handgrip strength related to long- term electromyography: Application for assessing functional decline in Parkinson disease. Arch Phys Med Rehabil 2017; 98: 347-352.

42. Nolana M, Provitera V, Estraneo A, Selim MM, Caporaso G, Stancanelli A, Saltalamacchia AM, Lanzillo B, Santoro L. Sensory deficit in Parkinson's disease: evidence of a cutaneous denervation. Brain 2008; 131: 1903-1911.

43. Gauntlett-Gibson J, Brown VJ. Reaction time deficits and Parkinson's disease. Neurosci Biobehav Rev 1998; 22: 865-881. Neurosci Methods 2005; 141: 29-39. detect subtle motor dysfunction in early Parkinson's disease. Mov Disord 2010; 25: $1150-1156$.

46. Koop MM, Shivitz N, Brontë-Stewart H. Quantitative measures of fine motor, limb, and postural bradykinesia in very early stage, untreated Parkinson's disease. Mov Disord 2008; 23: 1262-1268.

47. Taylor Tavares AL, Jefferis GS, Koop M, Hill BC, Hastie T, Heit G, Bronte-Stewart HM. Quantitative measurements of alternating finger tapping in Parkinson's disease correlate with UPDRS motor disability and reveal the improvement in fine motor control from medication and deep brain stimulation. Mov Disord 2005; 20: 1286-1298.

48. Lee MS, Lyoo CH, Lee MJ, Sim J, Cho H, Choi YN. Impaired finger dexterity in patients with parkinson's disease correlates with discriminative cutaneous sensory dysfunction. Mov Disord 2010; 25: 2531-2135. 
566

567

568

569

570

571

572

573

574

575

576

577

578

579

580

581

582

583

584

585

586

587

588

589

590

591

592

593

594

595

596

49. Yaholam G, Simon ES, Thorne R, Peretz C, Giladi N. Hand rhythmic tapping and timing in Parkinson's disease. Parkinsonism Relat Disord 2004; 10: 143-148.

50. Memedi M, Kahn T, Grenholm P, Nyholm D, Westkin. Automatic and objective assessment of alternating tapping performance in Parkinson's disease. Sensors 2013; 13: 16965-16984.

51. Lee CY, Kang SJ, Hong SK, Ma HI, Lee U, Kim YJ. A validation study of a smartphonebased finger tapping application for quantitative assessment of bradykinesia in Parkinson's disease. PLoS One 2016; 11: e0158852.

52. Djurić-Jovičić M, Petrovic I, Ječmenica-Lukić M, Radovanović S, Dragašević-Mišković N, Belić M, Miler-Jerković V, Popović MB, Kostić VS. Finger tapping analysis in patients with Parkinson's disease and atypical parkinsonism. Journal of Clinical Neuroscience 2016; 30: 49-55.

53. Zia S, Cody F, O’Boyle D. Joint position sense is impaired by Parkinson's disease. Ann Neurol 2000; 47: 218-228.

54. Maschke M, Gomez CM, Tuite PJ, Konczak J. Dysfunction of the basal ganglia, but not the cerebellum, impairs kinaesthesia. Brain 2003; 126: 2312-2322.

55. Konczak J, Krawczewski K, Tuite P, Maschke M. The perception of passive motion in Parkinson's disease. J Neurol 2007; 254: 655-663.

56. Ponsen M, Daffertshofer A, van den Heuvel E, Wolters ECh, Beek PJ, Berendse HW. Bimanual coordination dysfunction in early, untreated Parkinson's disease. Parkinsonism Relat Disord 2006; 12: 246-252.

57. van den Berg C, Beek PJ, Wagenaar RC, van Wieringen PC. Coordination disorders in patients with Parkinson's disease: a study of paced rhythmic forearm movements. Exp Brain Res 2000; 134: 174-186.

58. Almeida QJ, Wishart LR, Lee TD. Bimanual coordination deficits with Parkinson's disease: the influence of movement speed and external cueing. Mov Disord 2002; 17: 3037.

59. Barrantes S, Sánchez Egea AJ, González Rojas HA, Martí MJ, Compta Y, Valldeoriola F, Simo Mezquita E, Tolosa E, Valls-Solè J. Differential diagnosis between Parkinson's disease and essential tremor using the smartphone's accelerometer. PLoS One 2017; 25; 12: $\mathrm{e} 0183843$. 
597

598

599

600

601

602

603

604

605

606

607

608

609

610

611

612

613

614

615

616

617

618

619

620

621

622

623

624

625

626

60. Lukšys D, Jonaitis G, Griškevičius J. Quantitative analysis of parkinsonian tremor in a clinical setting using inertial measurement units. Parkinson's Disease 2018; Article ID 1683831.

61. Corcos DM, Chen CM, Quinn NP, McAuley J, Rothwell JC. Strength in Parkinson's disease: relationship to rate of force generation and clinical status. Ann Neurol 1996; 39: $79-88$.

62. Stelmach GE, Worringham CJ. The preparation and production of isometric force in Parkinson's disease. Neuropsychologia 1988; 26: 93-103.

63. Kunesch E, Schnitzler A, Tyercha C, Knecht S, Stelmach G. Altered force release control in Parkinson's disease. Mov Disord 2005; 20: 441-450.

64. Schneider JS, Diamond SG, Markham CH. Parkinson's disease: sensory and motor problems in arms and hands. Neurology 1987; 37: 951-956.

65. O'Suilleabhain P, Bullard J, Dewey RB. Proprioception in Parkinson's disease is acutely depressed by dopaminergic medications. J Neurol Neurosurg Psychiatry 2001; 71: 607610.

66. Proske U, Gandevia SC. The proprioceptive senses: Their roles in signaling body shape, body position and movement and muscle force. Physiol Rev 2012; 92: 1651-1697.

67. Proske U, Gandevia SC. Kinesthetic senses. Compr Physiol 2018; 8: 1157- 1183.

68. Quincy A, Brown M. Is DOPA-Responsive Hypokinesia Responsible for Bimanual Coordination Deficits in Parkinson's Disease? Front Neurol 2013; 4: 89.

69. Harrison J, Henderson L, Kennard C. Abnormal refractoriness in patients with Parkinson's disease after brief withdrawal of levodopa treatment. J Neurol Neurosurg Psychiatry 1995; 59: 499-506.

70. Velasco F, Velasco M. A quantitative evaluation of the effects of L-Dopa on Parkinson's disease. Neuropharmacology 1973; 12: 89-99.

71. Bloxham CA, Dick DJ, Moore M. Reaction times and attention in Parkinson's disease. $J$ Neurol Neurosurg Psychiatry 1987; 50: 178-183.

72. Puliman SL, Watts RL, Juncas JL, Chase TN, Sanes JN. Dopaminergic effects on simple and choice reaction time performance in Parkinson's disease. Neurology 1988; 38: 249254. 
627

628

629

630

631

632

633

634

635

636

637

638

639

640

641

642

643

644

645

646

647

648

649
73. Starkstein SE, Esteguy M, Berthier ML, Garcia H, Leiguarda R. Evoked potentials, reaction time and cognitive performance in on and off phases of Parkinson's disease. $J$ Neurol Neurosurg Psychiatry 1989; 52: 338-340.

74. Rafal RD, Posner MI, Walker JA, Friedrich FJ. Cognition and the basal ganglia. Separating the mental and motor components of performance in Parkinson's disease. Brain 1984; 107: 1083-1094.

75. Skorvanek M, Martinez-Martin P, Kovacs N, Rodriguez-Violante M, Corvol JC, Taba P, Seppi K, Levin O, Schrag A, Foltynie T, Alvarez-Sanchez M, Arakaki T, Aschermann Z, Aviles-Olmos I, Benchetrit E, Benoit C, Bergareche-Yarza A, Cervantes-Arriaga A, Chade A, Cormier F, Datieva V, Gallagher DA, Garretto N, Gdovinova Z, Gershanik O, Grofik M, Han V, Huang J, Kadastik-Eerme L, Kurtis MM, Mangone G, MartinezCastrillo JC, Mendoza-Rodriguez A, Minar M, Moore HP, Muldmaa M, Mueller C, Pinter B, Poewe W, Rallmann K, Reiter E, Rodriguez-Blazquez C, Singer C, Tilley BC, Valkovic P, Goetz CG, Stebbins GT. Differences in MDS-UPDRS scores based on Hoehn and Yahr stage and disease duration. Mov Disord Clin Pract 2017; 4: 536-544.

76. Müeller T, Benz S, Przuntek H. Tapping and peg insertion after levodopa intake in treated and de novo Parkinsonian patients. Can J Neurol Sci 2002; 29: 73-77.

77. McKay GN, Harrigan TP, Brašić JR. A low-cost quantitative continuous measurement of movements in the extremities of people with Parkinson's disease. MethodsX 2019; 6: 169-189.

78. Proud EL, Bilney B, Miller KJ, Morris ME, McGinley JL. Measuring hand dexterity in people with Parkinson's disease: reliability of pegboard tests. Am J Occup Ther 2019; 73: $7304205050 \mathrm{p} 1-7304205050 \mathrm{p} 8$. 


\section{Table $\mathbf{1}$ (on next page)}

Table 1

Parkinson's disease participant $(n=34)$, age- and gender-matched healthy control participant characteristics $(n=68)$ and $50+$ population group $(n=176)$. 
1 Table 1: Parkinson's disease participant $(n=34)$, age- and gender-matched healthy control participant characteristics $(n=68)$

2 and $50+$ population group $(n=176)$.

\begin{tabular}{|c|c|c|c|c|c|c|c|c|}
\hline & $\begin{array}{l}\text { Age: } \\
\text { mean } \\
\text { (range) }\end{array}$ & $\begin{array}{c}\text { Gender: } \\
\text { F:M (ratio } \\
\% \text { ) }\end{array}$ & $\begin{array}{l}\text { Handedness } \\
\text { (right) } \\
(\%)\end{array}$ & $\begin{array}{c}\text { Visual acuity } \\
\text { (logMAR) } \\
\text { (SD) }\end{array}$ & $\begin{array}{c}\text { Order of } \\
\text { testing: } \\
\text { 'Off' state } \\
\text { first (ratio } \\
\quad \% \text { ) }\end{array}$ & $\begin{array}{l}\text { Years with } \\
\text { PD: } \\
\text { median } \\
\text { (IQR) }\end{array}$ & $\begin{array}{l}\text { Hoehn and } \\
\text { Yahr scale: } \\
\text { mean } \\
\text { (range) }\end{array}$ & $\begin{array}{l}\text { DASH } \\
\text { score: } \\
\text { median } \\
(\mathrm{IQR})\end{array}$ \\
\hline PD group & $\begin{array}{c}68.6 \\
(47-87)\end{array}$ & $\begin{array}{c}12: 22 \\
(35: 65)\end{array}$ & $\begin{array}{c}29 \\
(85)\end{array}$ & $\begin{array}{c}0.26 \\
(0.20)\end{array}$ & $\begin{array}{c}27: 7 \\
(79: 21)\end{array}$ & $\begin{array}{c}5.0 \\
(3.0-10.0)\end{array}$ & $\begin{array}{c}2.7 \\
(1-4)\end{array}$ & $\begin{array}{c}36.6 \\
(18.6-48.7)\end{array}$ \\
\hline $\begin{array}{l}\text { Control } \\
\text { group }\end{array}$ & $\begin{array}{c}68.5 \\
(46-87)\end{array}$ & $\begin{array}{c}24: 44 \\
(35: 65)\end{array}$ & $\begin{array}{c}59 \\
(87)\end{array}$ & $\begin{array}{c}0.14 \\
(0.21)\end{array}$ & & & & $\begin{array}{c}3.0 \\
(0.8-8.8)\end{array}$ \\
\hline $\begin{array}{l}50+ \\
\text { population }\end{array}$ & $\begin{array}{c}70.1 \\
(50-96)\end{array}$ & $\begin{array}{c}94: 82 \\
(53: 47)\end{array}$ & $\begin{array}{l}161 \\
(92)\end{array}$ & $\begin{array}{c}0.11 \\
(0.18)\end{array}$ & & & & $\begin{array}{c}3.3 \\
(0.8-10.8)\end{array}$ \\
\hline
\end{tabular}

3 


\section{Table 2 (on next page)}

Table 2

Mean \pm SD or median (IQR) scores for PD group during their 'off' and 'on' medication states and non-PD controls for each test, mean or median difference $[95 \% \mathrm{Cl}]$ in performance between 'off' state PD and non-PD controls, and 'on' state PD and non-PD controls (independent t-tests or Mann-Whitney $U$ tests). 
1 Table 2: Mean \pm SD or median (IQR) scores for PD group during their 'off' and 'on' medication states and non-PD controls

2 for each test, mean or median difference [95\% CI] in performance between 'off' state PD and non-PD controls, and 'on' state

3 PD and non-PD controls (independent t-tests or Mann-Whitney $U$ tests).

\begin{tabular}{|c|c|c|c|c|c|}
\hline \multirow[t]{2}{*}{ Measure } & \multicolumn{2}{|c|}{$\begin{array}{l}\text { PD group } \\
(n=34)\end{array}$} & \multirow[t]{2}{*}{$\begin{array}{l}\text { Control group } \\
\quad(n=68)\end{array}$} & \multicolumn{2}{|c|}{ Difference } \\
\hline & 'Off' state & 'On' state & & 'Off' vs. control & 'On' vs. control \\
\hline Isometric elbow flexion strength $(\mathrm{kg})$ & $19.6 \pm 8.8$ & $20.9 \pm 9.3$ & $23.5 \pm 9.8$ & $3.9[0.1,7.7]$ & $2.6[-1.2,6.6]$ \\
\hline Handgrip strength $(\mathrm{kg})$ & $29.4 \pm 11.1$ & $29.2 \pm 11.1$ & $37.8 \pm 12.2$ & $8.4[3.7,12.8]^{* *}$ & $8.6[3.7,13.1]^{* * *}$ \\
\hline Finger-press reaction time $(\mathrm{ms})$ & $249.3(208.0-274.1)$ & $236.5(208.3-292.7)$ & $206.0(189.6-234.4)$ & $-43.3[-65.0,-11.0]^{\mathrm{a} * * *}$ & $-30.5[-73.6,-7.7]^{a * * *}$ \\
\hline Finger tapping (no. of taps) & $50.5(42.8-55.0)$ & $50.5(46.0-57.3)$ & $56.0(49.0-60.0)$ & $5.5[0.0,9.0]^{\mathrm{a} * *}$ & $5.3[1.7,9.7]^{* *}$ \\
\hline 9-hole peg test (s) & $28.2(24.1-35.9)$ & $25.0(22.1-32.6)$ & $21.5(19.5-23.7)$ & $-6.6[-9.5,-2.8]^{a * * *}$ & $-3.5[-7.4,-1.3]^{a * * *}$ \\
\hline Loop \& wire test (no. of touches) & $26.5(18.6-41.4)$ & $23.5(16.5-41.1)$ & $12.8(7.6-19.9)$ & $-13.8[-20.8,-6.5]^{a * * *}$ & $-10.8[-21.0,-5.0]^{\text {a*** }}$ \\
\hline Position sense $\left(^{\circ}\right)$ & $4.8(3.4-6.9)$ & $4.4(2.4-5.7)$ & $2.6(1.8-3.8)$ & $-2.2[-3.6,-1.1]^{\mathrm{a} * * *}$ & $-1.8[-2.9,-0.8]^{a * *}$ \\
\hline Tactile sensitivity (g) & $0.28(0.07-0.40)$ & $0.12(0.07-0.40)$ & $0.07(0.04-0.16)$ & $-0.21[-0.33,0.00]^{a * *}$ & $-0.05[-0.33,0.00]^{a *}$ \\
\hline Two-point discrimination $(\mathrm{mm})$ & $3.8 \pm 1.1$ & $3.6 \pm 1.0$ & $3.6 \pm 1.1$ & $-0.2[-0.7,0.3]$ & $0.0[-0.4,0.4]$ \\
\hline Two-line discrimination (mm) & $2.3(2.0-2.5)$ & $2.3(1.9-2.7)$ & $2.2(1.9-2.4)$ & $-0.1[-0.3,0.1]^{\mathrm{a}}$ & $-0.1[-0.4,0.0]^{\mathrm{a}}$ \\
\hline Bimanual pole test (s) & $20.4(16.9-39.5)$ & $19.1(16.0-37.6)$ & $18.1(14.4-25.1)$ & $-2.3[-10.7,0.7]^{a *}$ & $-0.9[-11.7,1.7]^{\mathrm{a}}$ \\
\hline Arm stability - Eyes open $\left(^{\circ}\right)$ & $54.5(40.0-93.4)$ & $52.5(38.6-80.1)$ & $39.6(33.9-48.7)$ & $-14.9[-33.0,-2.3]^{a * * *}$ & $-13.0[-29.2,0.9]^{\mathrm{a} * *}$ \\
\hline Arm stability - Eyes closed $\left(^{\circ}\right)$ & $50.7(39.5-86.9)$ & $52.6(37.1-94.5)$ & $40.5(33.3-48.2)$ & $-10.2[-24.5,-0.7]^{\mathrm{a} * *}$ & $-12.2[-28.5,0.8]^{\mathrm{a} * *}$ \\
\hline Arm stability - Weight eyes open $\left(^{\circ}\right)$ & $58.3(43.2-105.6)$ & $55.4(41.8-77.2)$ & $46.8(38.2-56.5)$ & $-11.4[-44.8,1.2]^{\mathrm{a} * *}$ & $-8.6[-24.8,4.0]^{a *}$ \\
\hline Arm stability - Weight eyes closed $\left(^{\circ}\right)$ & $68.9(44.7-100.9)$ & $58.0(40.9-98.3)$ & $46.4(39.7-53.8)$ & $-22.5[-39.8,-7.3]^{a * * *}$ & $-11.6[-34.3,1.7]^{\mathrm{a} *}$ \\
\hline Shirt task (s) & $75.1(45.0-112.0)$ & $67.7(39.0-111.8)$ & $32.9(26.4-39.9)$ & $-42.2[-64.8,-18.3]^{a * * *}$ & $-34.8[-51.1,-17.9]^{\mathrm{a} * * *}$ \\
\hline DASH questionnaire & $36.6(18.5-48.7)$ & & $3.0(0.8-8.8)$ & $-33.6[-44.7,-25.5]^{a * * *}$ & \\
\hline
\end{tabular}

4 aMann-Whitney U test performed for non-parametric variables, differences reported as median [95\% CI].

$5 \quad * p<0.05, * * p<0.01, * * * p<0.001$, uncorrected. 


\section{Table 3 (on next page)}

Table 3

Pearson product moment correlations $(r)$ or Spearman rho correlations between individual test performance and age, duration of Parkinson's disease (Duration), Hoehn and Yahr (HY) score, and Disabilities of the Shoulder, Arm and Hand (DASH) questionnaire score during their 'off' and 'on' medication states. 
Table 3: Pearson product moment correlations (r) or Spearman rho correlations between individual test performance and age,

2 duration of Parkinson's disease (Duration), Hoehn and Yahr (HY) score, and Disabilities of the Shoulder, Arm and Hand

3 (DASH) questionnaire score during their 'off' and 'on' medication states.

\begin{tabular}{|c|c|c|c|c|c|c|c|c|}
\hline \multirow[t]{2}{*}{ Measure } & \multicolumn{4}{|c|}{ 'Off' state } & \multicolumn{4}{|c|}{ 'On' state } \\
\hline & Age & Duration & HY & DASH & Age & Duration & HY & DASH \\
\hline Isometric elbow flexion strength (kg) & -.296 & $.139^{\mathrm{a}}$ & -.321 & $-.576^{* *}$ & $-.438 * *$ & $.201^{\mathrm{a}}$ & -.297 & $-.531 * *$ \\
\hline Handgrip strength $(\mathrm{kg})$ & $-.479 * *$ & $.236^{\mathrm{a}}$ & -.325 & $-.562 * *$ & $-.517 * *$ & $.232^{\mathrm{a}}$ & -.315 & $-.549 * *$ \\
\hline Finger-press reaction time $(\mathrm{ms})$ & $.132^{\mathrm{a}}$ & $.199^{a}$ & $.643^{\mathrm{a} * * *}$ & $.470^{\mathrm{a} * *}$ & .277 & $.356^{\mathrm{a} *}$ & $.579^{* *}$ & $.510 * *$ \\
\hline Finger tapping (no. of taps) & $-.061^{\mathrm{a}}$ & $-.114^{\mathrm{a}}$ & $-.195^{\mathrm{a}}$ & $-.052^{\mathrm{a}}$ & -.266 & $-.056^{\mathrm{a}}$ & $-.404 *$ & -.169 \\
\hline 9-hole peg test (s) & $.175^{\mathrm{a}}$ & $.294^{\mathrm{a}}$ & $.476^{\mathrm{a} * *}$ & $.487 \mathrm{a} * *$ & $.402^{\mathrm{a} *}$ & $.297^{\mathrm{a}}$ & $.529^{a * *}$ & $.396^{\mathrm{a} *}$ \\
\hline Loop and wire test (no. of touches) & $.222^{\mathrm{a}}$ & $.290^{\mathrm{a}}$ & $.425^{\mathrm{a} *}$ & $.298^{\mathrm{a}}$ & $.267^{\mathrm{a}}$ & $.317^{\mathrm{a}}$ & $.391^{\mathrm{a} *}$ & $.100^{\mathrm{a}}$ \\
\hline Position sense $\left(^{\circ}\right)$ & $-.143^{\mathrm{a}}$ & $.178^{\mathrm{a}}$ & $.179^{\mathrm{a}}$ & $.188^{\mathrm{a}}$ & $.057^{\mathrm{a}}$ & $.227^{\mathrm{a}}$ & $.137^{\mathrm{a}}$ & $.105^{\mathrm{a}}$ \\
\hline Tactile sensitivity $(\mathrm{g})$ & $.232^{\mathrm{a}}$ & $.202^{\mathrm{a}}$ & $.212^{\mathrm{a}}$ & $.171^{\mathrm{a}}$ & .328 & $.385^{\mathrm{a} *}$ & .285 & .136 \\
\hline Two-point discrimination (mm) & $.440 * *$ & $.192^{\mathrm{a}}$ & $.375^{*}$ & $.552 * *$ & .295 & $.115^{\mathrm{a}}$ & .315 & .251 \\
\hline Two-line discrimination (mm) & $.089^{\mathrm{a}}$ & $.181^{\mathrm{a}}$ & $.262^{\mathrm{a}}$ & $.160^{\mathrm{a}}$ & $.036^{\mathrm{a}}$ & $.312^{\mathrm{a}}$ & $.014^{\mathrm{a}}$ & $.161^{\mathrm{a}}$ \\
\hline Bimanual pole test (s) & $.362^{\mathrm{a} *}$ & $.286^{\mathrm{a}}$ & $.407^{\mathrm{a} *}$ & $.492^{\mathrm{a} * *}$ & $.308^{\mathrm{a}}$ & $.312^{\mathrm{a}}$ & $.346^{\mathrm{a} *}$ & $.448^{\mathrm{a} * *}$ \\
\hline Arm stability - Eyes open $\left(^{\circ}\right)$ & $-.026^{\mathrm{a}}$ & $.185^{\mathrm{a}}$ & $.271^{\mathrm{a}}$ & $.261^{\mathrm{a}}$ & $-.011^{\mathrm{a}}$ & $.263^{\mathrm{a}}$ & $.333^{\mathrm{a}}$ & $.329^{a}$ \\
\hline Arm stability - Eyes closed $\left(^{\circ}\right)$ & $-.087^{\mathrm{a}}$ & $.227^{\mathrm{a}}$ & $.244^{\mathrm{a}}$ & $.213^{\mathrm{a}}$ & $-.016^{\mathrm{a}}$ & $.187^{\mathrm{a}}$ & $.390^{\mathrm{a} *}$ & $.373^{\mathrm{a} *}$ \\
\hline Arm stability - Weight eyes open $\left(^{\circ}\right)$ & $-.031^{\mathrm{a}}$ & $.200^{\mathrm{a}}$ & $.294^{\mathrm{a}}$ & $.311^{\mathrm{a}}$ & $.009^{\mathrm{a}}$ & $.237^{\mathrm{a}}$ & $.342^{\mathrm{a} *}$ & $.301^{\mathrm{a}}$ \\
\hline Arm stability - Weight eyes closed $\left(^{\circ}\right)$ & $-.024^{\mathrm{a}}$ & $.229^{\mathrm{a}}$ & $.276^{\mathrm{a}}$ & $.248^{\mathrm{a}}$ & $.057^{\mathrm{a}}$ & $.184^{\mathrm{a}}$ & $.332^{\mathrm{a}}$ & $.305^{\mathrm{a}}$ \\
\hline Shirt task (s) & $.299^{\mathrm{a}}$ & $.082^{\mathrm{a}}$ & $.539^{a * *}$ & $.374^{a *}$ & $.287^{\mathrm{a}}$ & $.173^{\mathrm{a}}$ & $.489^{\mathrm{a} * *}$ & $.356^{\mathrm{a} *}$ \\
\hline
\end{tabular}

4 Note: Negative values for isometric elbow flexion strength; handgrip strength and finger tapping indicate worsening performance with

5 increasing age, duration, HY score and DASH score. Positive values for all other tests indicate worsening performance.

6 aSpearman's rho correlation reported for non-parametric variables.

$7 \quad * p<0.05, * * p<0.01, * * * p<0.001$, uncorrected.

8 


\section{Table 4 (on next page)}

\section{Table 4}

Mean \pm SD or median (IQR) scores for 'off' state and 'on' state for each test, mean or median difference $[95 \% \mathrm{Cl}]$ in performance between 'off' and 'on' states (paired t-tests or Wilcoxon matched pairs test). 
1 Table 4: Mean \pm SD or median (IQR) scores for 'off' state and 'on' state for each test, mean or median difference [95\% CI] in 2 performance between 'off' and 'on' states (paired t-tests or Wilcoxon matched pairs test).

\begin{tabular}{|c|c|c|c|c|}
\hline Measure & 'Off' state & 'On' state & $p$ & Difference \\
\hline Isometric elbow flexion strength $(\mathrm{kg})$ & $19.6 \pm 8.8$ & $20.9 \pm 9.3$ & $0.036^{*}$ & $0.9[-0.4,1.7]^{\mathrm{a}}$ \\
\hline Handgrip strength $(\mathrm{kg})$ & $29.4 \pm 11.1$ & $29.2 \pm 11.1$ & 0.813 & $-0.2[-1.8,1.1]$ \\
\hline Finger-press reaction time $(\mathrm{ms})$ & $249.3(208.0-274.1)$ & $236.5(208.3-292.7)$ & 0.762 & $-2.5[-16.5,15.2]$ \\
\hline Finger tapping (no. of taps) & $50.5(42.8-55.0)$ & $50.5(46.0-57.3)$ & 0.252 & $1.3[-0.9,3.6]$ \\
\hline 9-hole peg test (s) & $28.2(24.1-35.9)$ & $25.0(22.1-32.6)$ & $0.006^{* *}$ & $-2.4[-4.1,-0.6]^{\mathrm{a}}$ \\
\hline Loop and wire test (no. of touches) & $26.5(18.6-41.4)$ & $23.5(16.5-41.1)$ & 0.229 & $-1.9[-5.1,1.1]$ \\
\hline Position sense $\left(^{\circ}\right)$ & $4.8(3.4-6.9)$ & $4.4(2.4-5.7)$ & $0.017 *$ & $-0.4[-1.4,-0.0]^{\mathrm{a}}$ \\
\hline Tactile sensitivity $(\mathrm{g})$ & $0.28(0.07-0.40)$ & $0.12(0.07-0.40)$ & 0.072 & $0.00[0.00,0.00]^{\mathrm{a}}$ \\
\hline Two-point discrimination (mm) & $3.8 \pm 1.1$ & $3.6 \pm 1.0$ & 0.242 & $-0.2[-0.6,0.1]$ \\
\hline Two-line discrimination (mm) & $2.3(2.0-2.5)$ & $2.3(1.9-2.7)$ & 0.623 & $0.0[-0.1,0.2]$ \\
\hline Bimanual pole test (s) & $20.4(16.9-39.5)$ & $19.1(16.0-37.6)$ & $0.032 *$ & $-1.0[-3.0,-0.2]^{\mathrm{a}}$ \\
\hline Arm stability - Eyes open $\left(^{\circ}\right)$ & $54.5(40.0-93.4)$ & $52.5(38.6-80.1)$ & 0.614 & $-0.5[-2.6,1.4]^{\mathrm{a}}$ \\
\hline Arm stability - Eyes closed $\left(^{\circ}\right)$ & $50.7(39.5-86.9)$ & $52.6(37.1-94.5)$ & 0.791 & $-1.2[-5.5,6.4]^{\mathrm{a}}$ \\
\hline Arm stability - Weight eyes open $\left(^{\circ}\right)$ & $58.3(43.2-105.6)$ & $55.4(41.8-77.2)$ & $0.017 *$ & $-3.7[-15.3,-1.6]^{\mathrm{a}}$ \\
\hline Arm stability - Weight eyes closed $\left(^{\circ}\right)$ & $68.9(44.7-100.9)$ & $58.0(40.9-98.3)$ & $0.023 *$ & $-3.6[-14.7,-2.3]^{\mathrm{a}}$ \\
\hline Shirt task (s) & $75.1(45.0-112.0)$ & $67.7(39.0-111.8)$ & 0.060 & $-5.8[-10.9,0.0]^{\mathrm{a}}$ \\
\hline
\end{tabular}

3 a'Wilcoxon matched pairs test performed when distribution of differences between 'off' and 'on' states were non-parametric.

4 Difference between 'on' and 'off' state reported as median [95\% CI].

$5 \quad{ }^{*} p<0.05, * * p<0.01$, uncorrected. 


\section{Table 5 (on next page)}

\section{Table 5}

Validity, feasibility and reliability weightings for the upper limb PPA tests in people with Parkinson's disease. 
1 Table 5: Validity, feasibility and reliability weightings for the upper limb PPA tests in people with Parkinson's disease.

\begin{tabular}{|c|c|c|c|c|c|c|}
\hline Measure & $<$ Healthy $^{\mathrm{a}}$ & $\mathrm{DASH}^{\mathrm{a}}$ & L-dopa & Feasible & Reliable [20] & Total \\
\hline Isometric elbow flexion strength & 0 & 1 & 1 & 0 & 1 & 3 \\
\hline Handgrip strength & 1 & 1 & 0 & 1 & 1 & 4 \\
\hline Finger-press reaction time & 1 & 1 & 0 & 1 & 1 & 4 \\
\hline Finger tapping & 1 & 0 & 0 & 1 & 1 & 3 \\
\hline 9-hole peg test & 1 & 1 & 1 & 1 & 1 & 5 \\
\hline Loop and wire test & 1 & 0 & 0 & 0 & 1 & 2 \\
\hline Position sense & 1 & 0 & 1 & 1 & 0 & 3 \\
\hline Tactile sensitivity & 1 & 0 & 0 & 1 & 1 & 3 \\
\hline Two-point discrimination & 0 & 0 & 0 & 1 & 1 & 2 \\
\hline Two-line discrimination & 0 & 0 & 0 & 1 & 0 & 1 \\
\hline Bimanual pole test & 0 & 1 & 1 & 1 & 1 & 4 \\
\hline Arm stability - Eyes open & 1 & 0 & 0 & 1 & 1 & 3 \\
\hline Arm stability - Eyes closed & 1 & 1 & 0 & 1 & 1 & 4 \\
\hline Arm stability - Weight eyes open & 1 & 0 & 1 & 1 & 1 & 4 \\
\hline Arm stability - Weight eyes closed & 1 & 0 & 1 & 1 & 1 & 4 \\
\hline Shirt task & 1 & 1 & 0 & 1 & 1 & 4 \\
\hline
\end{tabular}

2 'Weightings calculated for PD group during 'on' state

$3<$ Healthy (Independent t-test or Mann-Whitney U test $p$-values): $1-p<.05,0-p \geq .05$ (uncorrected).

4 DASH (Pearson correlation $r$-values): $1-p<.05 ; 0-p \geq .05$ (uncorrected).

5 L-dopa (Paired t-test $p$-values): $1-p<.05 ; 0-p \geq .05$ (uncorrected).

6 Reliability (test/re-test reliability): $1-\mathrm{ICC} \geq 0.7 ; 0-\mathrm{ICC}<0.7$ or not calculable.

7 Feasibility:

81 -minimal equipment required, short administration time.

90 -requires bulky or insufficiently robust testing equipment. 


\section{Figure 1}

Differences in performance in each test of the upper limb PPA between people with PD and age- and sex-matched healthy.

Test scores from the PD group performed during their 'off' medication state. Blue circles represent each individual PD participant's test score for that particular test, while orange circles represent each individual control participant's test score. The black circle located along the right axis of each graph represents the mean or median difference (depending on the distribution of the test scores in each group) in test scores between the PD group and the age- and sex-matched control group. Error bars depict $95 \%$ confidence intervals. Note: due to missing data, a small number of control group test scores $(n=1-13)$ do not contain a complete set of 68 observations. 
A

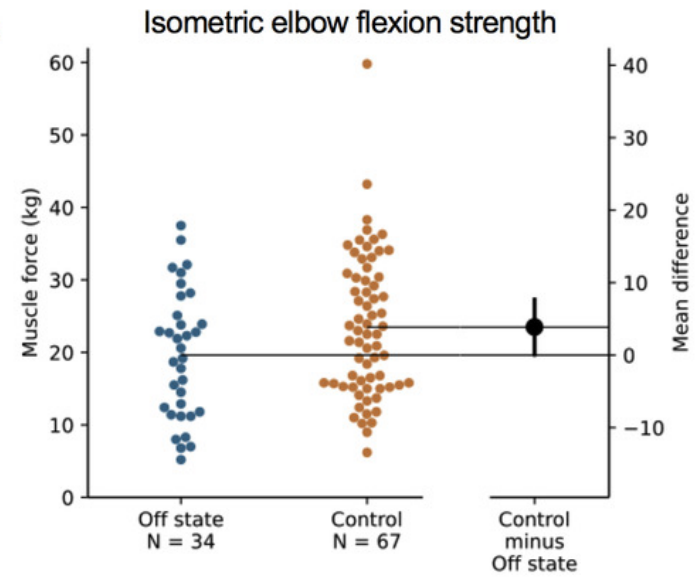

C

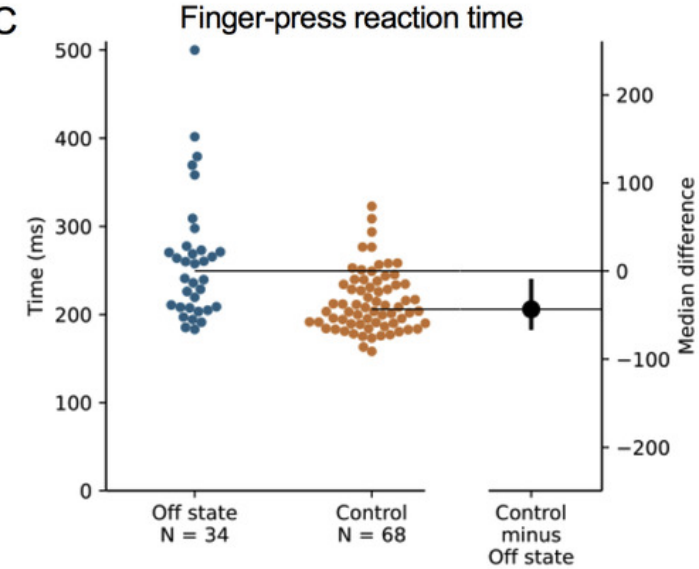

E

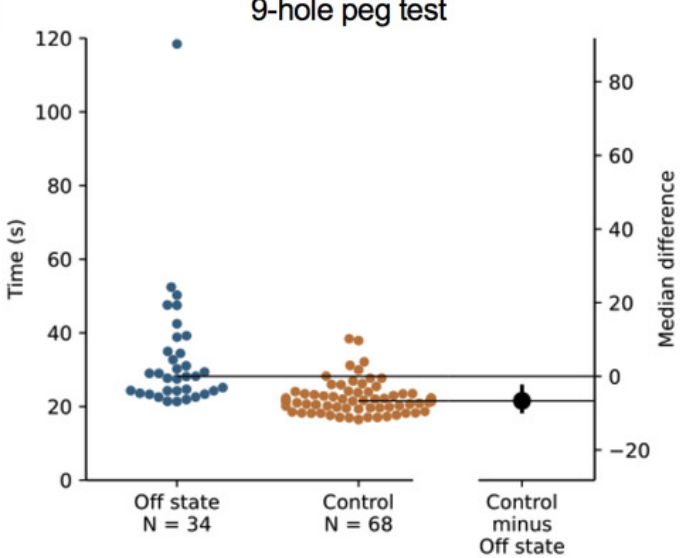

G

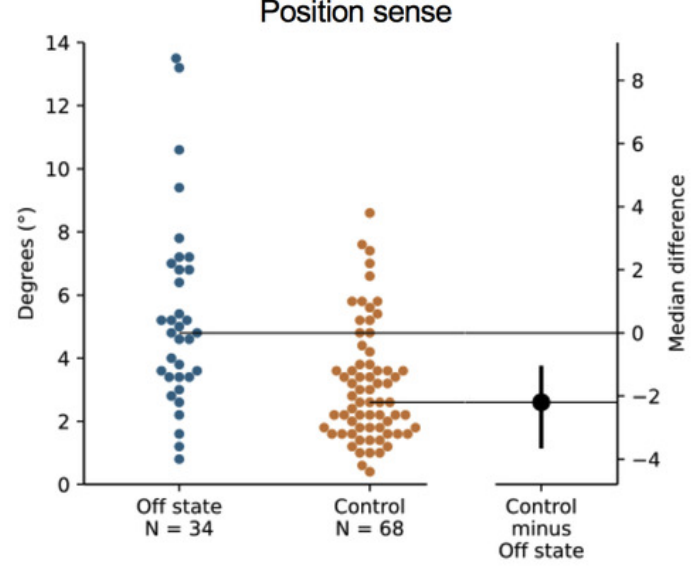

B

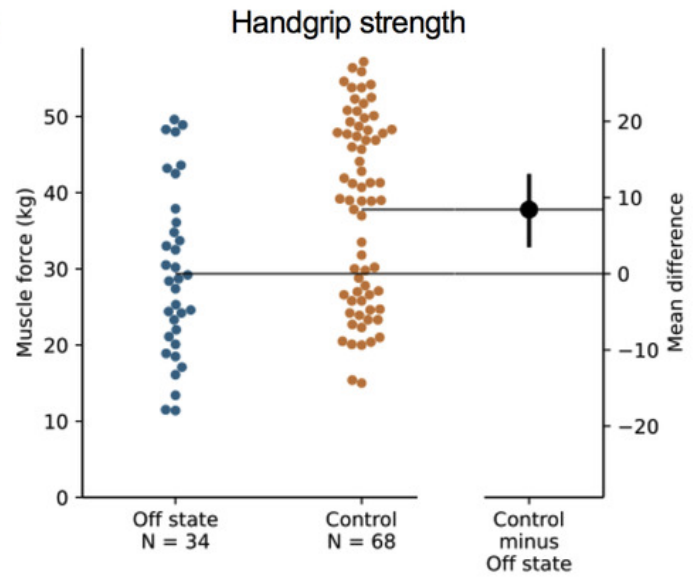

D

Finger tapping

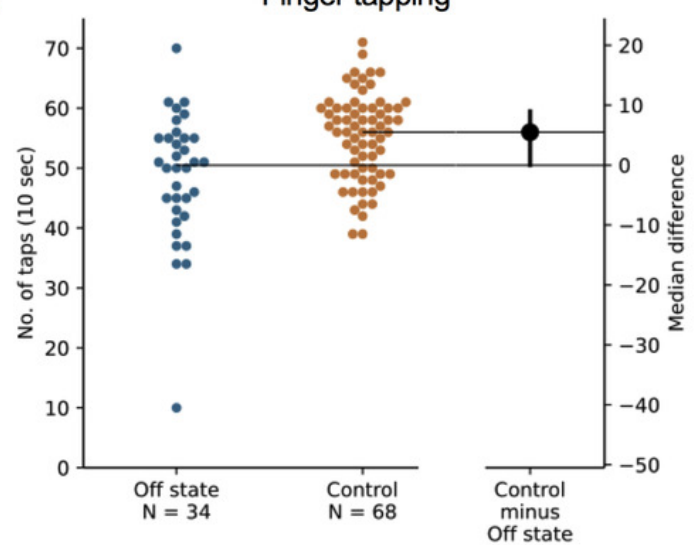

$\mathrm{F}$

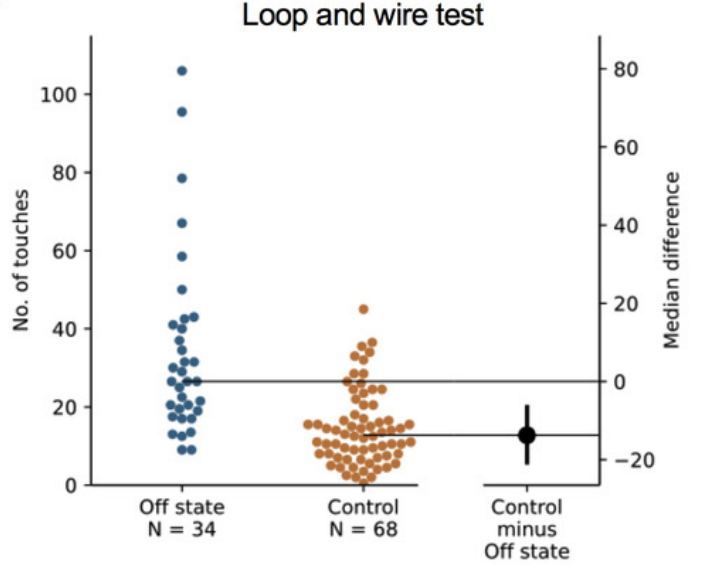

$\mathrm{H}$

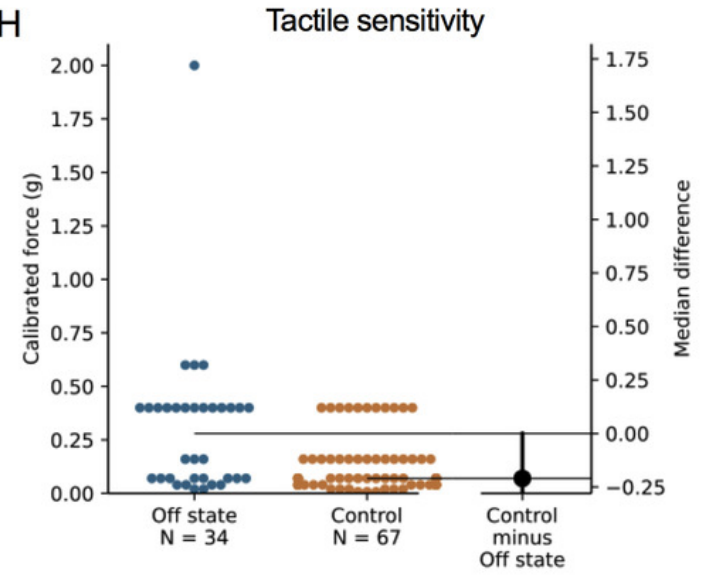




\section{Figure 2}

Differences in performance in each test of the upper limb PPA between people with PD and age- and sex-matched healthy.

Test scores from the PD group performed during their 'off' medication state. Blue circles represent each individual PD participant's test score for that particular test, while orange circles represent each individual control participant's test score. The black circle located along the right axis of each graph represents the mean or median difference (depending on the distribution of the test scores in each group) in test scores between the PD group and the age- and sex-matched control group. Error bars depict $95 \%$ confidence intervals. Note: due to missing data, a small number of control group test scores $(n=1-13)$ do not contain a complete set of 68 observations. 
A

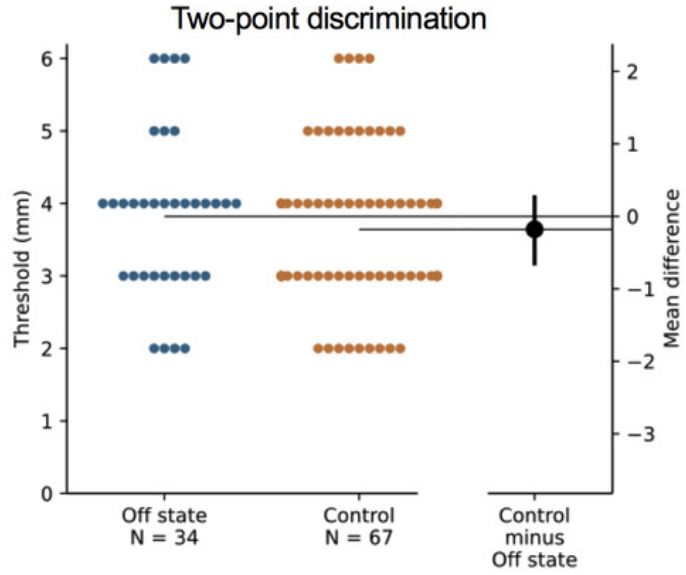

C

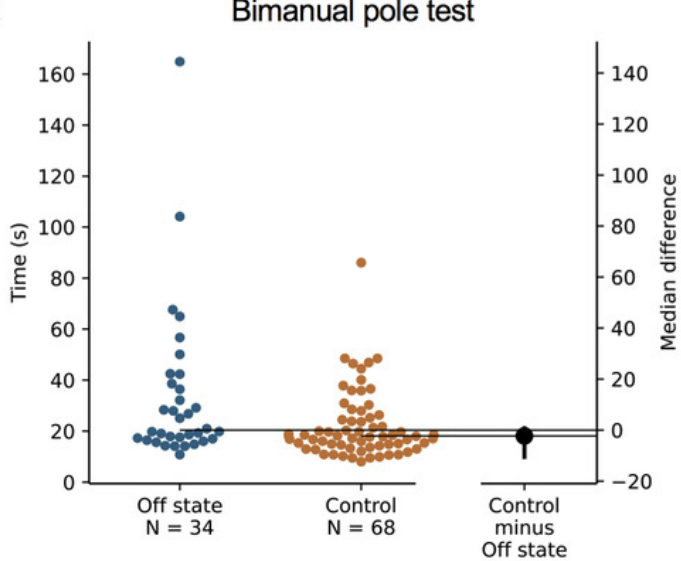

E

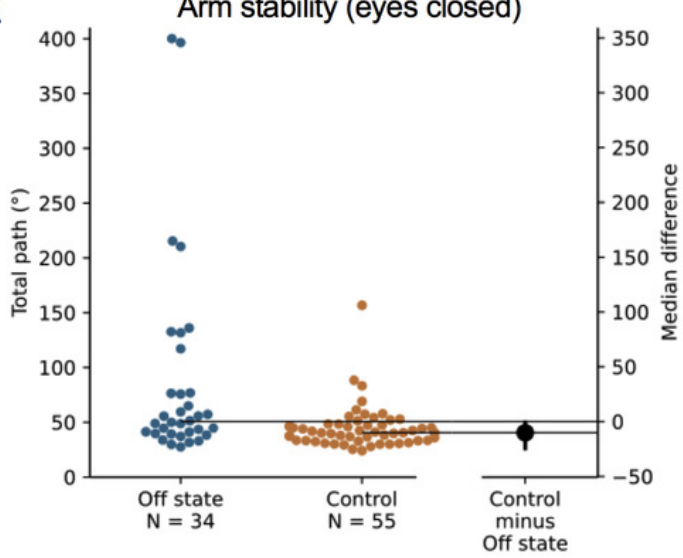

G

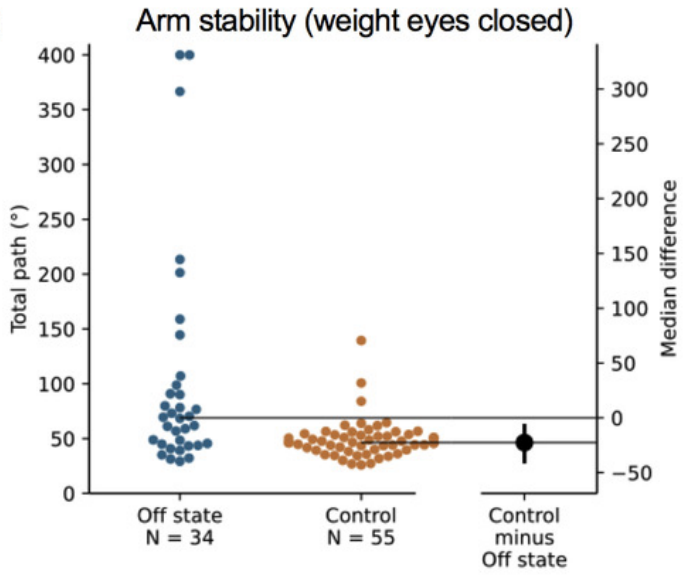

B

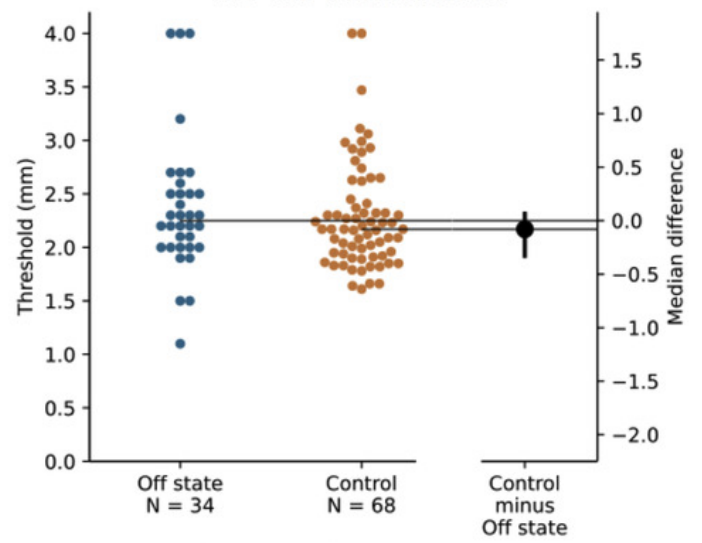

D

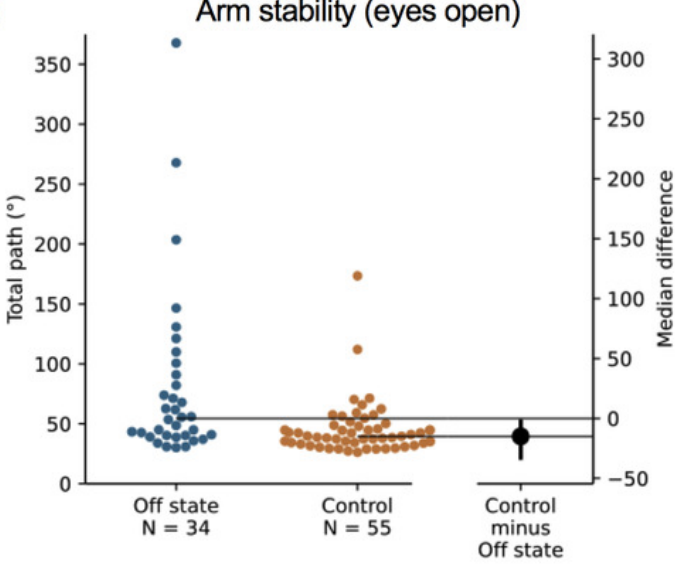

F

Arm stability (weight eyes open)

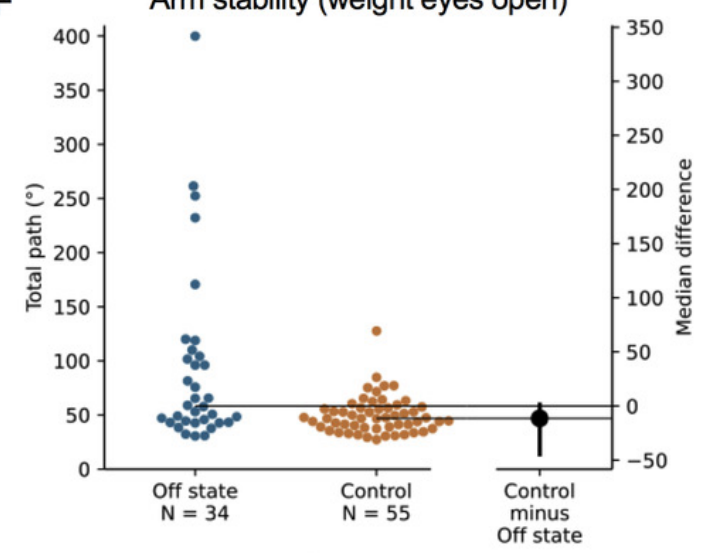

$\mathrm{H}$

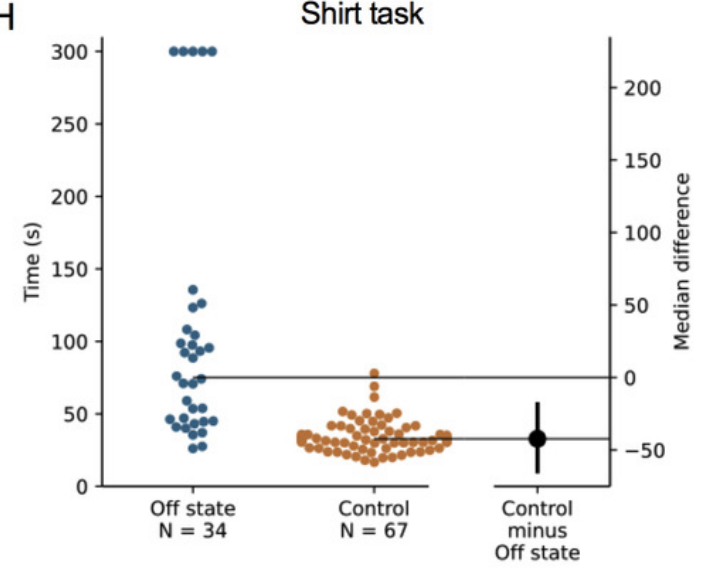




\section{Figure 3}

Differences in performance in each test of the upper limb PPA between people with PD and age- and sex-matched healthy.

Test scores from the PD group performed during their 'on' medication state. Blue circles represent each individual PD participant's test score for that particular test, while orange circles represent each individual control participant's test score. The black circle located along the right axis of each graph represents the mean or median difference (depending on the distribution of the test scores in each group) in test scores between the PD group and the age- and sex-matched control group. Error bars depict $95 \%$ confidence intervals. Note: due to missing data, a small number of control group test scores $(n=1-13)$ do not contain a complete set of 68 observations. 
A

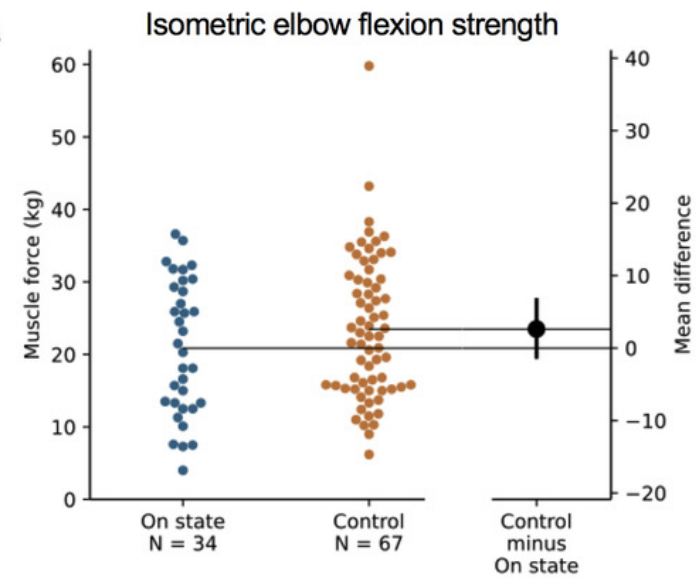

C

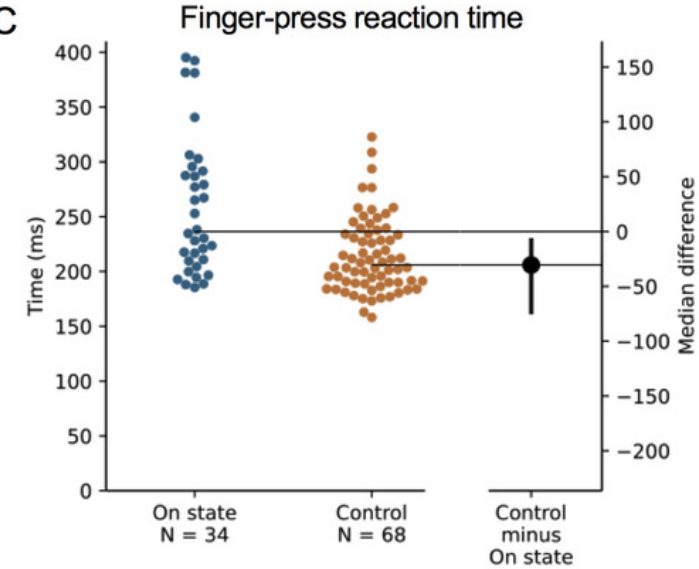

E

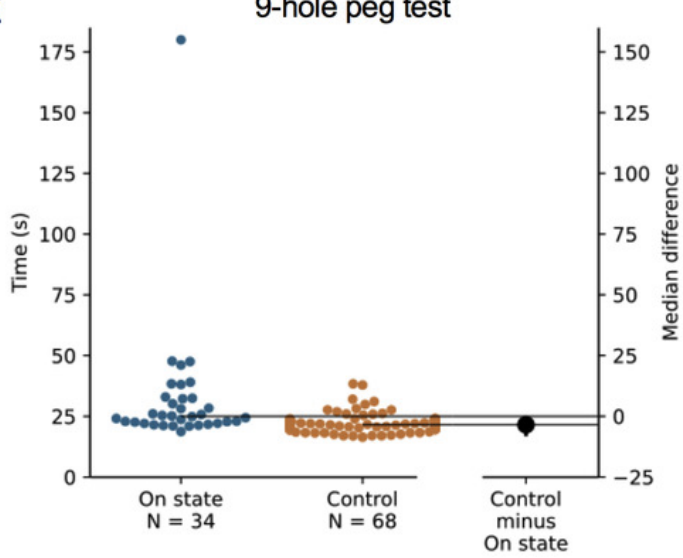

G

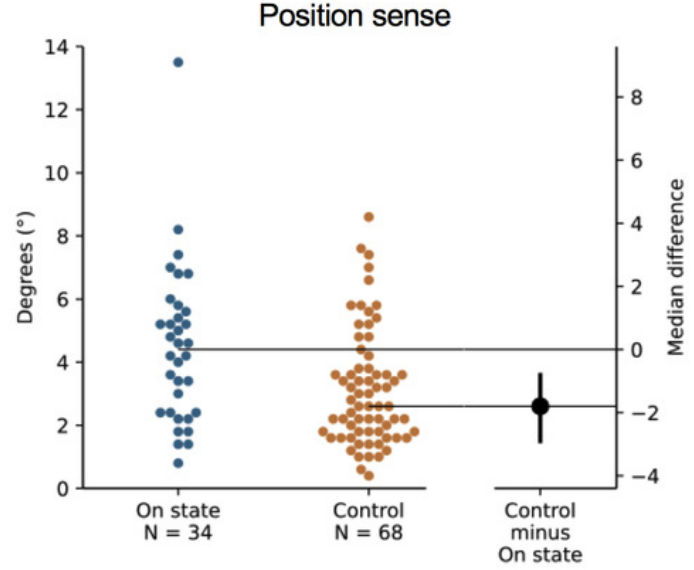

B

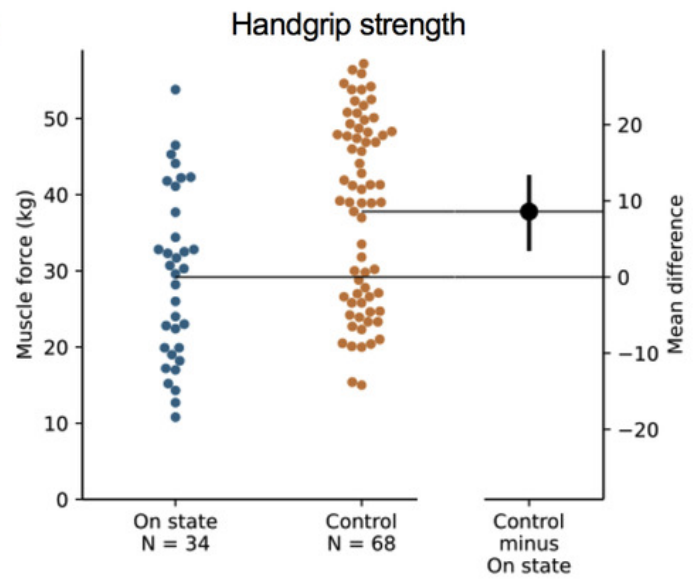

D

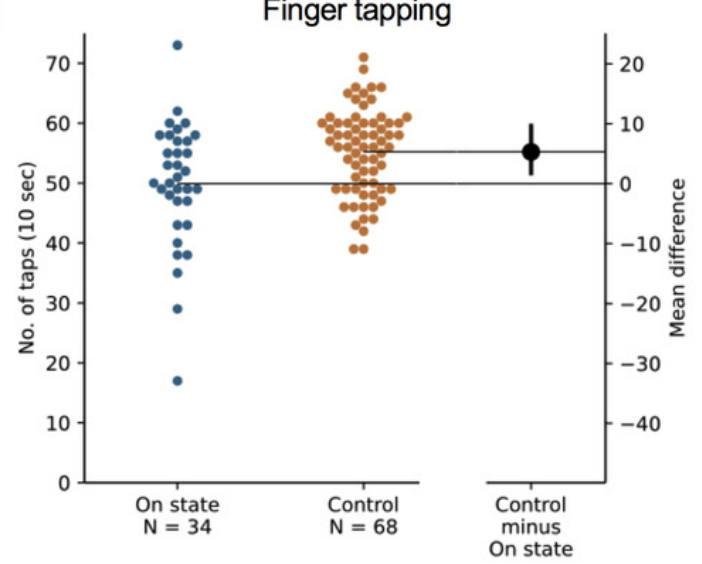

$\mathrm{F}$

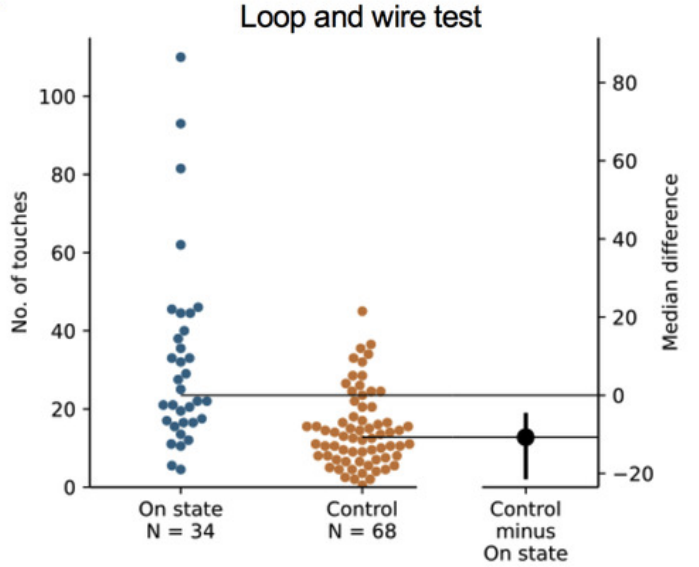

$\mathrm{H}$

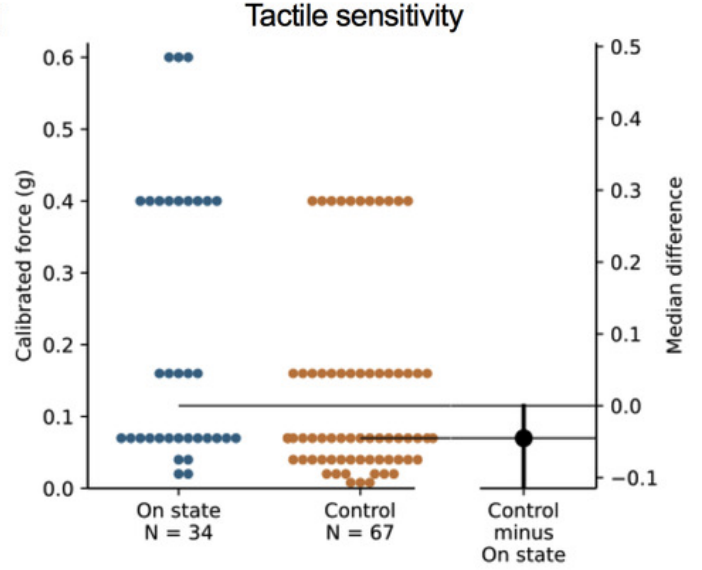




\section{Figure 4}

Differences in performance in each test of the upper limb PPA between people with PD and age- and sex-matched healthy.

Test scores from the PD group performed during their 'on' medication state. Blue circles represent each individual PD participant's test score for that particular test, while orange circles represent each individual control participant's test score. The black circle located along the right axis of each graph represents the mean or median difference (depending on the distribution of the test scores in each group) in test scores between the PD group and the age- and sex-matched control group. Error bars depict $95 \%$ confidence intervals. Note: due to missing data, a small number of control group test scores $(n=1-13)$ do not contain a complete set of 68 observations. 
A

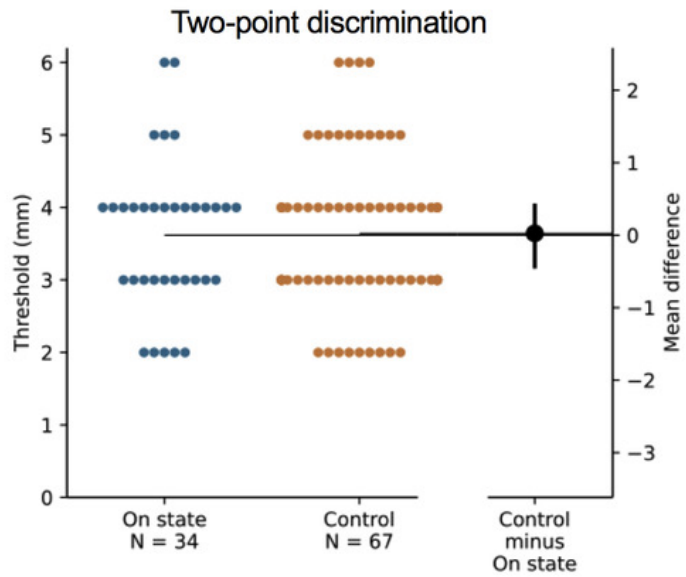

C

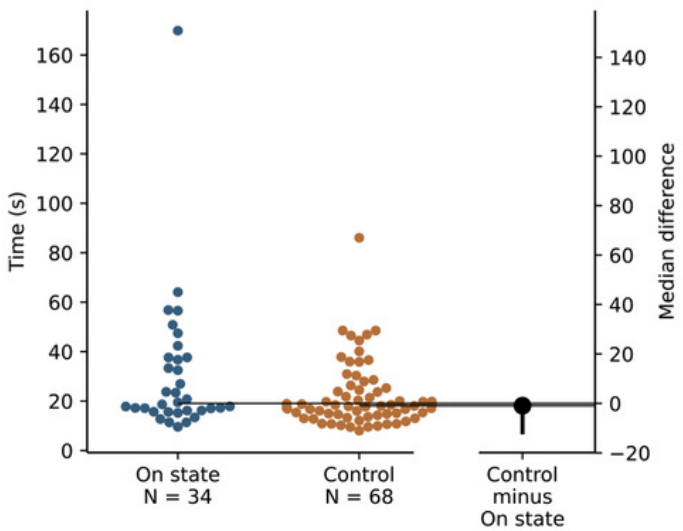

E

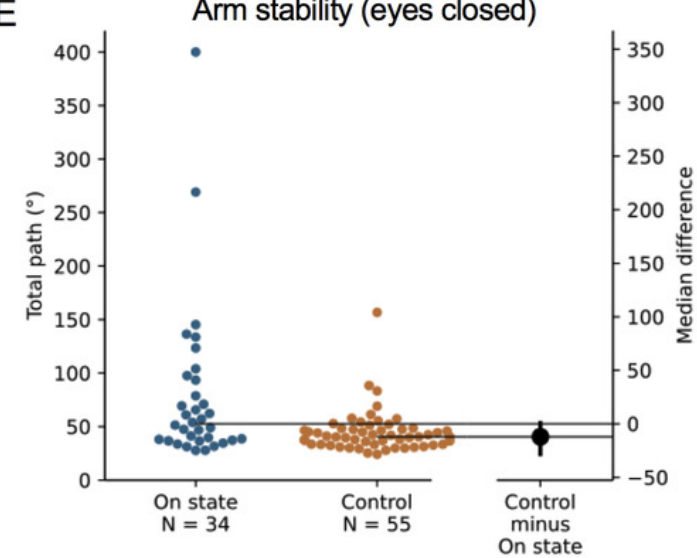

G

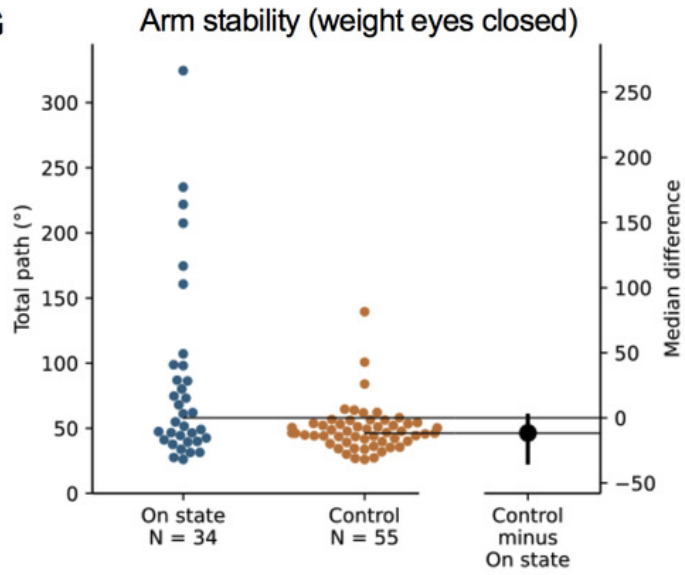

B

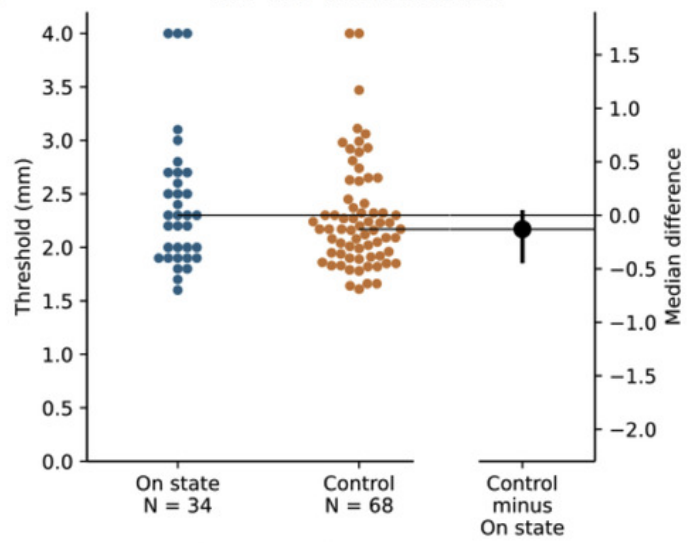

D

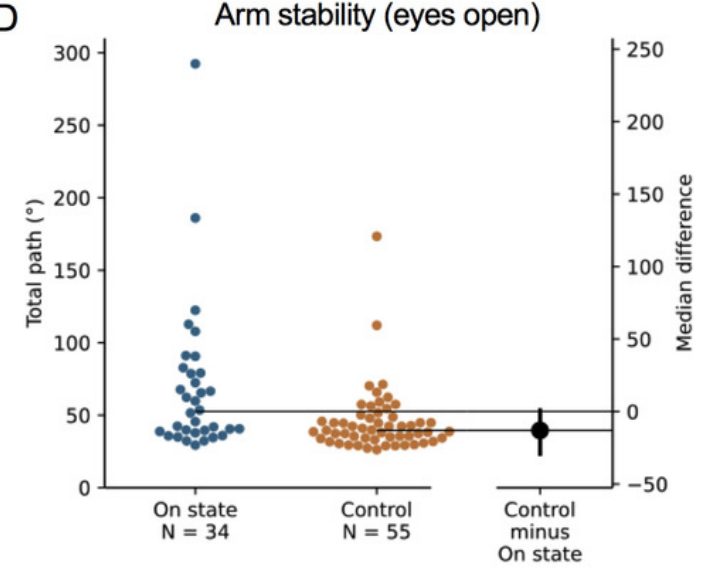

F

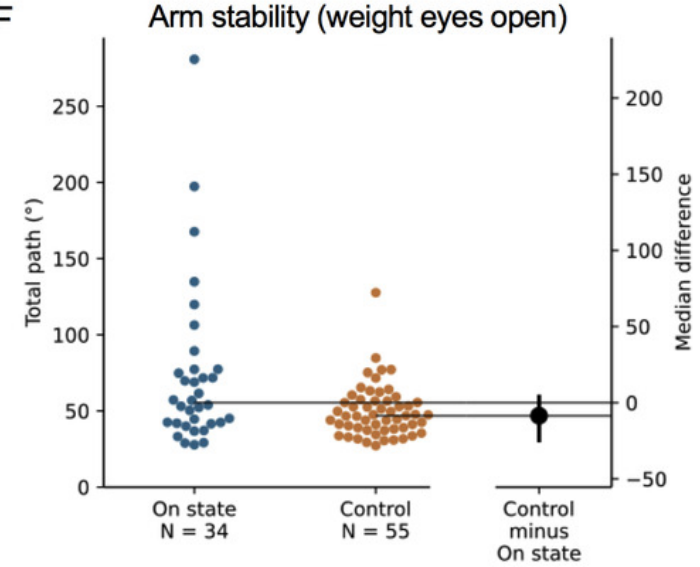

H

Shirt task

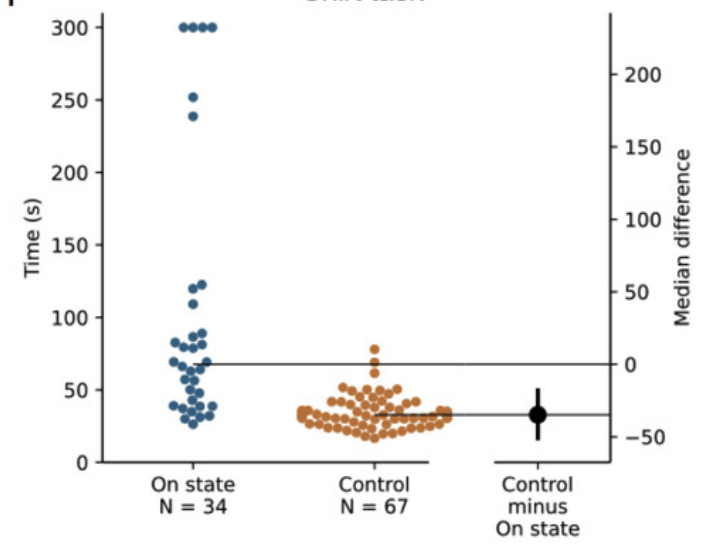




\section{Figure 5}

Upper limb Physiological Profile Assessment (PPA) test scores presented as standardised ( $z$ ) scores for the PD group during the 'off' and 'on' medication states referenced to a cohort of people aged $50+$ years without PD.

Test scores are presented as standardised ( $\mathrm{z}$ ) scores to allow direct comparison in performance between each test both within and between individuals. Each unit represents one standard deviation. A score of zero indicates an average level of performance compared to the reference population without PD, while negative scores represent below-average

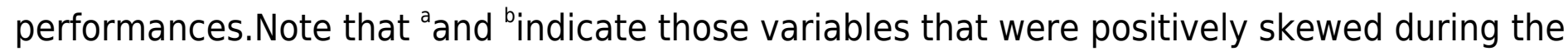
'off' and 'on' states, respectively, and therefore converted to their logarithmic form prior to calculation of their z-scores. Abbreviations: EO, eyes open; EC, eyes closed; WEO, weight eyes open; WEC, weight eyes closed. 
'Off' vs. 'on' medication

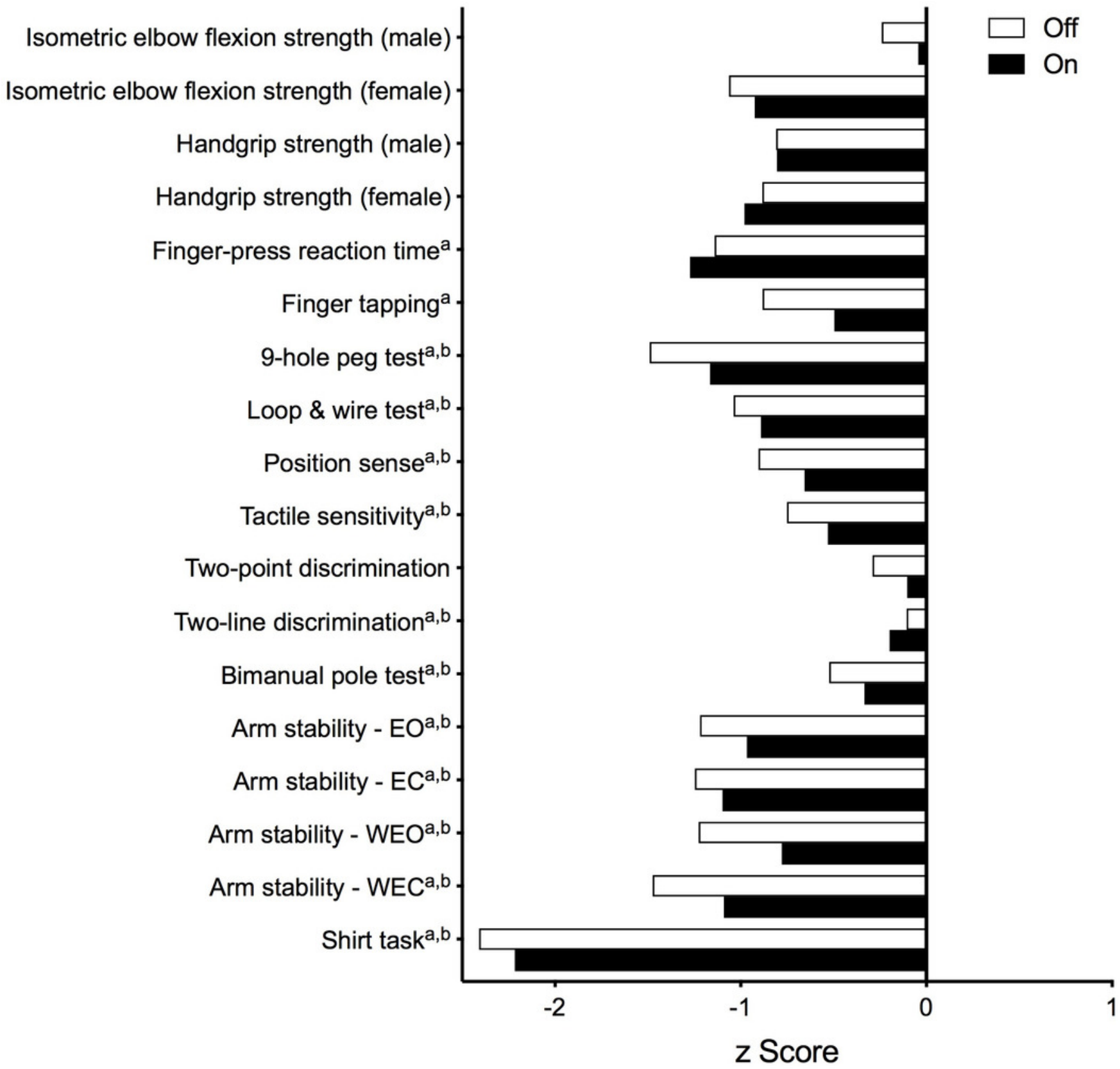




\section{Figure 6}

Upper limb physiological performance profiles of four individuals with PD, highlighting the inter-individual variability of upper limb motor impairment associated with PD.

Test scores are presented as standardised ( $z$ ) scores referenced to a normative database of individuals from the general population aged 50 years and over. (A)A 58-year old male ( $\mathrm{HY}=$ 2.0) demonstrating clear differences in performance between the 'off' and 'on' medication states in measures of arm stability. (B)A 73-year old male ( $\mathrm{HY}=1.0)$ who, despite below average muscle strength, displays above average levels of performance across all remaining physiological domains. (C)In contrast, a 63-year old male (HY = 3.0) who, with the exception of finger tapping speed, scores well below average in all other physiological domains. (D)A 71-year old female $(\mathrm{HY}=3.0)$ with a mixed presentation, showing above average performance in measures of proximal muscle strength, motor speed and skin sensation while appearing impaired in reaction time, dexterity and functional tasks. Note: strength test scores are adjusted for gender. Note that ${ }^{a}$ and ${ }^{b}$ indicate those variables that were positively skewed during the 'off' and 'on' states, respectively, and therefore converted to their logarithmic form prior to calculation of their z-scores. Note: z-scores are capped at -4.5 in Figure 1C. Abbreviations: EO, eyes open; EC, eyes closed; WEO, weight eyes open; WEC, weight eyes closed. 
A

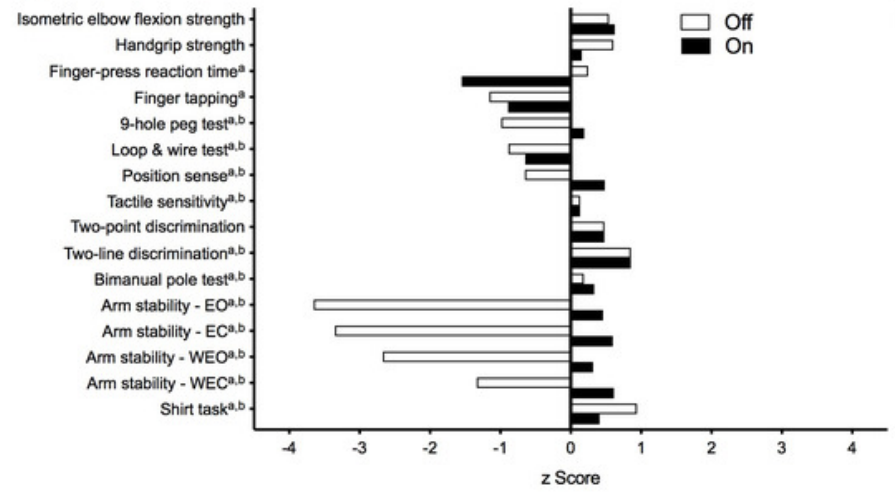

C

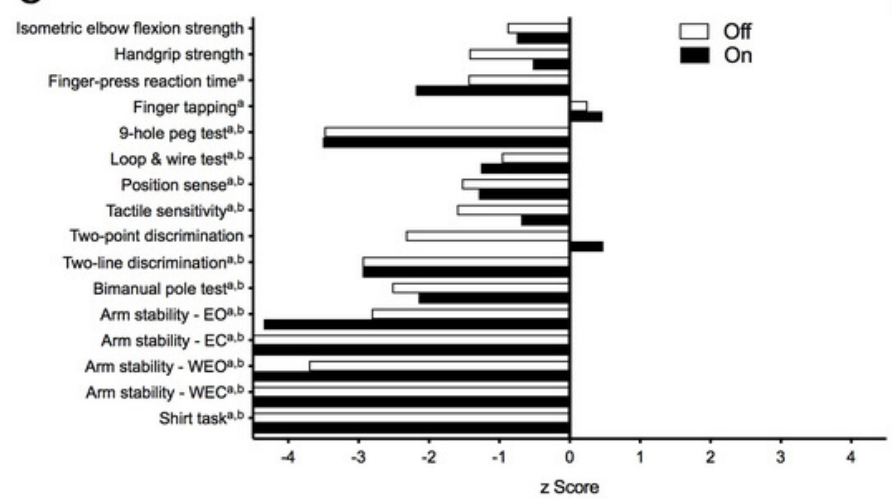

B

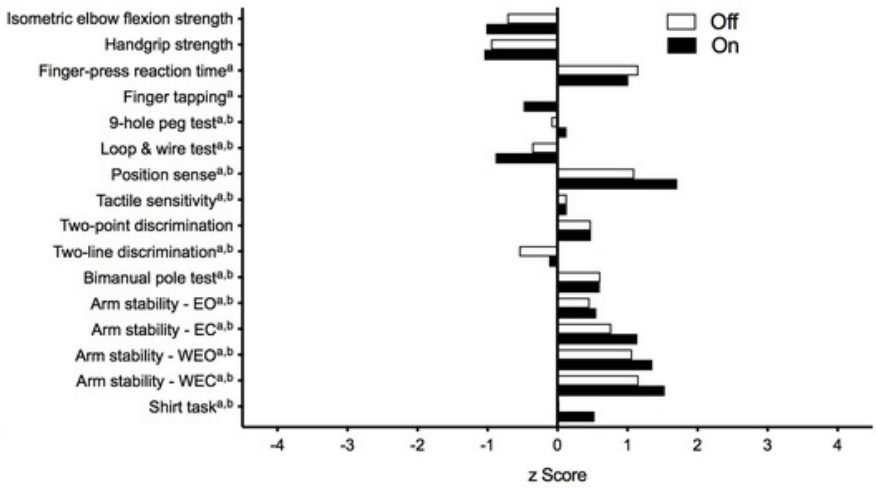

D

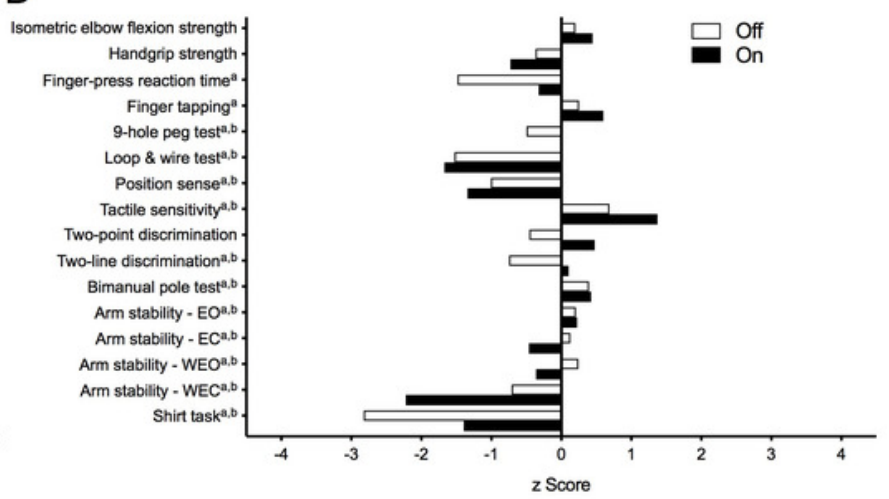




\section{Figure 7}

Comparisons of test scores in each test of the upper limb PPA between the 'off' and 'on' medication states in people with PD.

Each grey line plotted along the left axis of each graph represents the change in performance between the 'off' medication state (left-side of the line) and the 'on' medication state (right-side of the line) of each individual PD participant. The black circle located along the right axis of each graph represents the mean or median difference (depending on the distribution of the differences in test scores between medication states) in test scores between the 'off and 'on' medication states. Error bars depict 95\% confidence intervals. 
A Isometric elbow flexion strength

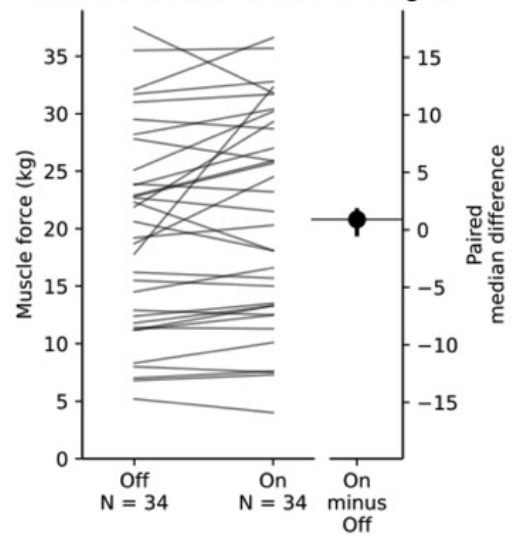

C Finger-press reaction time

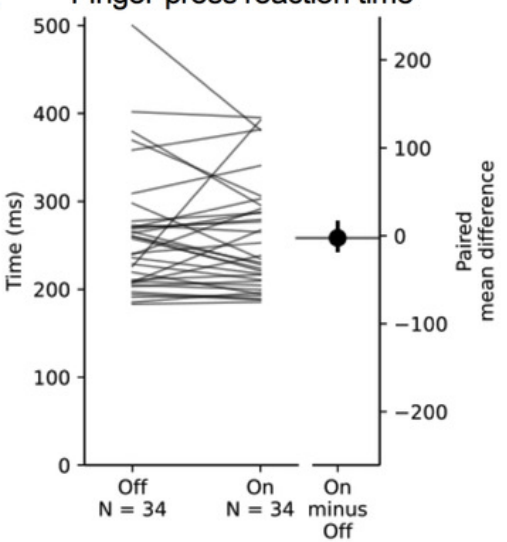

E

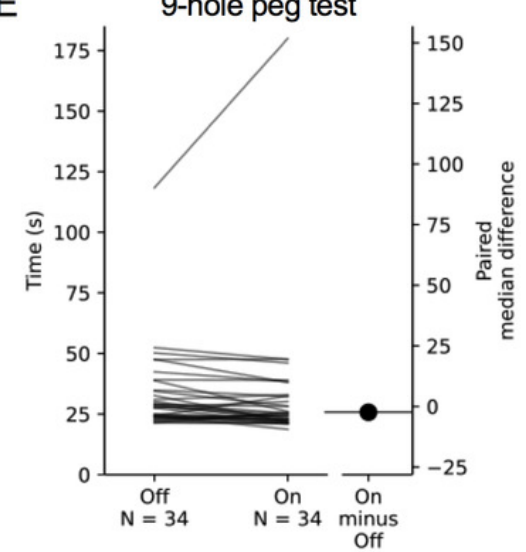

G

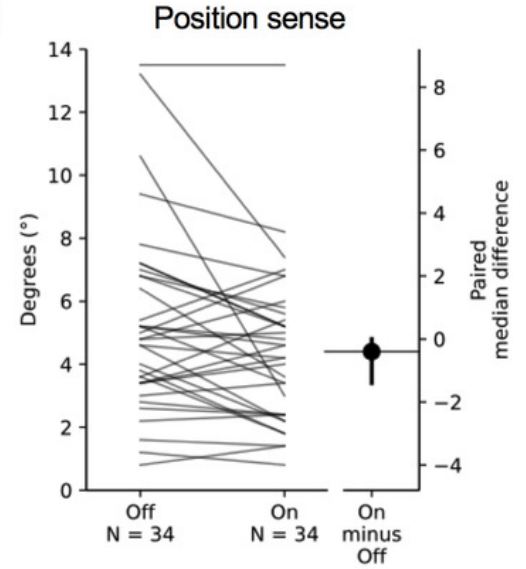

B

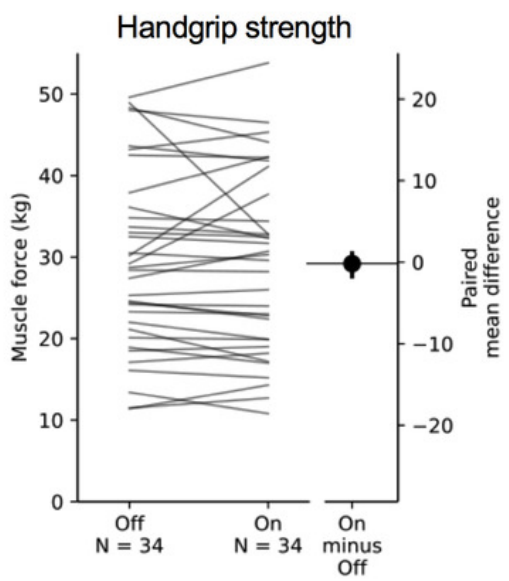

D

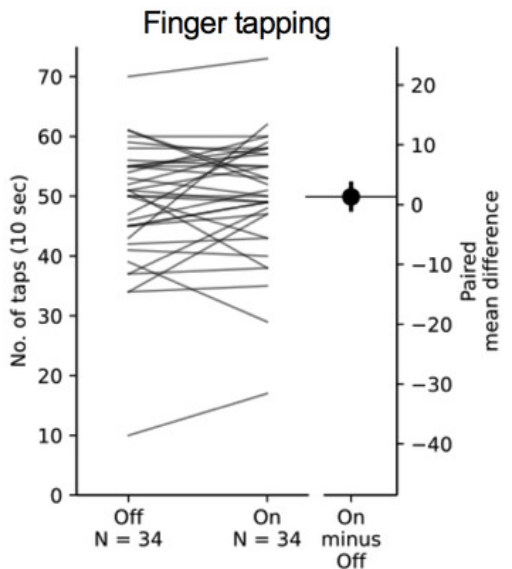

F

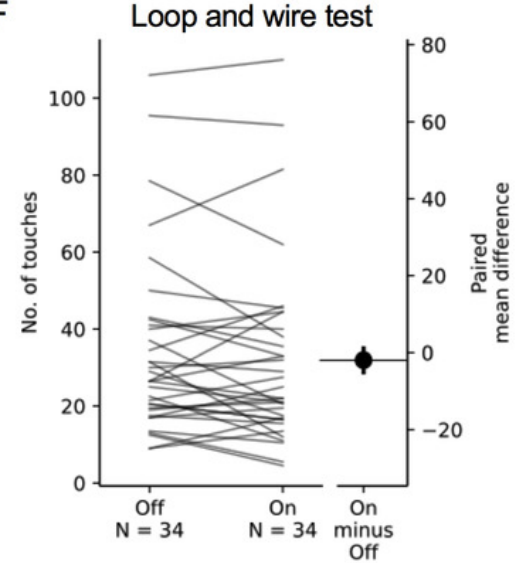

$\mathrm{H}$

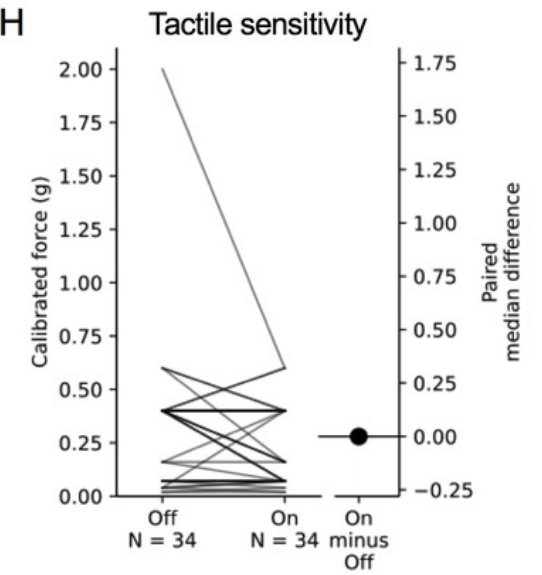




\section{Figure 8}

Comparisons of test scores in each test of the upper limb PPA between the 'off' and 'on' medication states in people with PD.

Each grey line plotted along the left axis of each graph represents the change in performance between the 'off' medication state (left-side of the line) and the 'on' medication state (right-side of the line) of each individual PD participant. The black circle located along the right axis of each graph represents the mean or median difference (depending on the distribution of the differences in test scores between medication states) in test scores between the 'off and 'on' medication states. Error bars depict 95\% confidence intervals. 
A

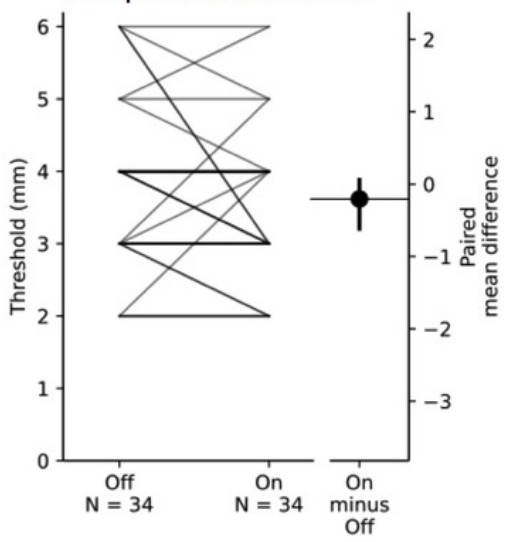

C

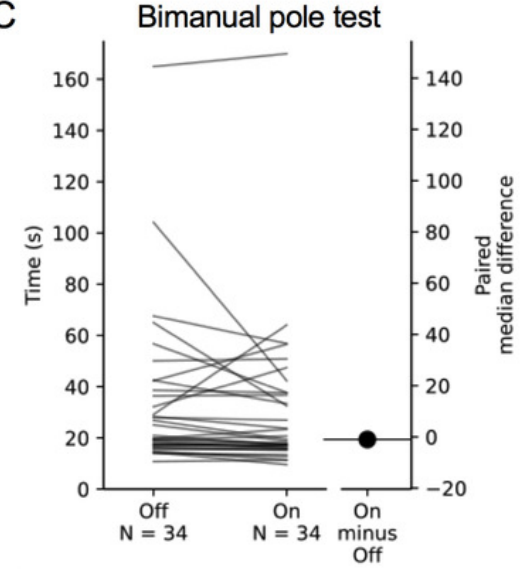

E Arm stability (eyes closed)

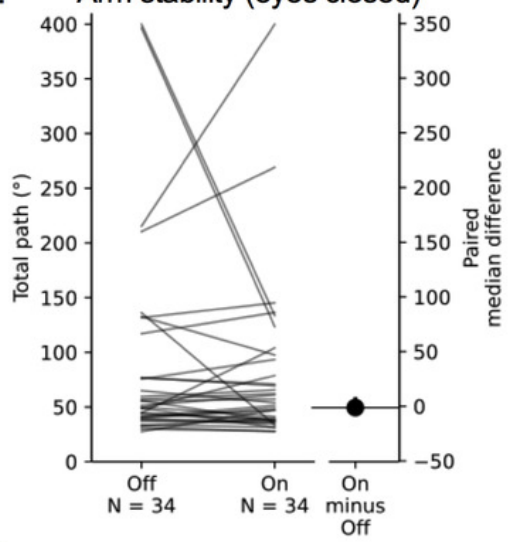

G Arm stability (weight eyes closed)

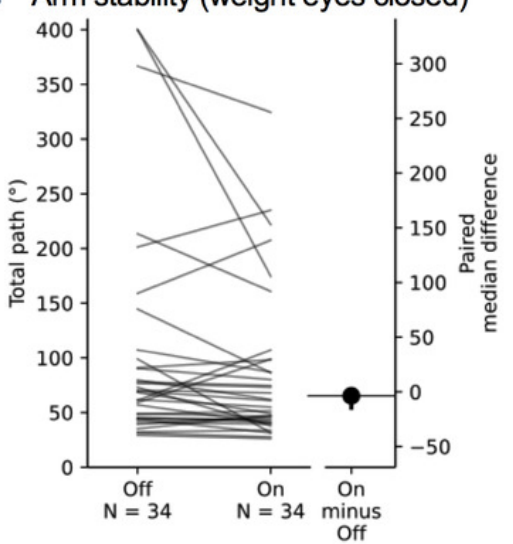

B Two-line discrimination

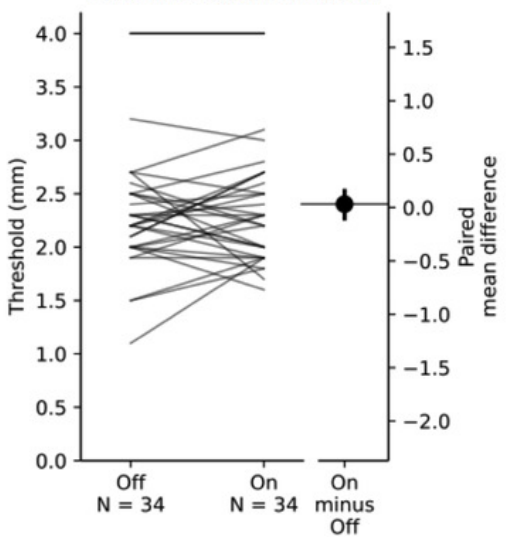

D Arm stability (eyes open)

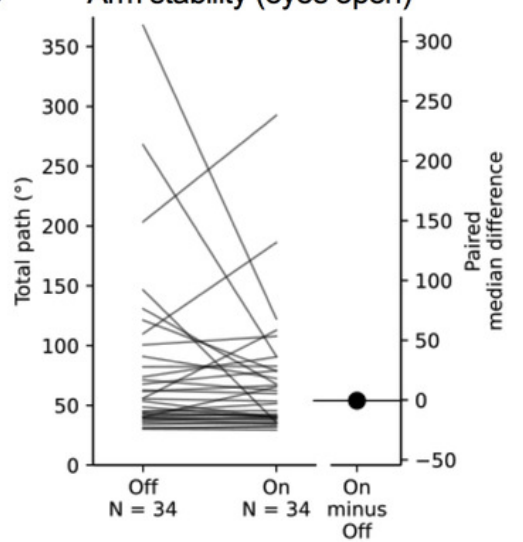

F Arm stability (weight eyes open)

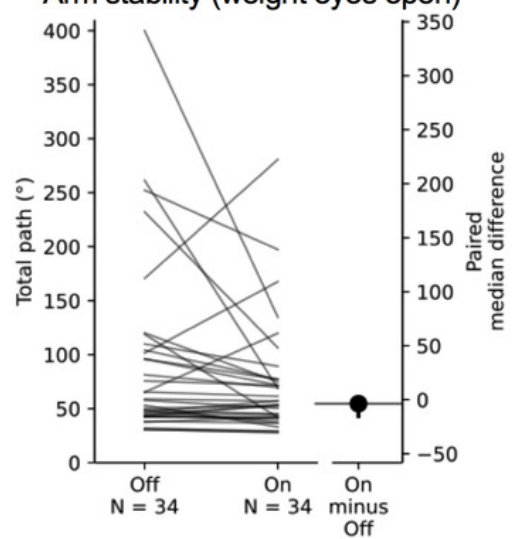

$\mathrm{H}$

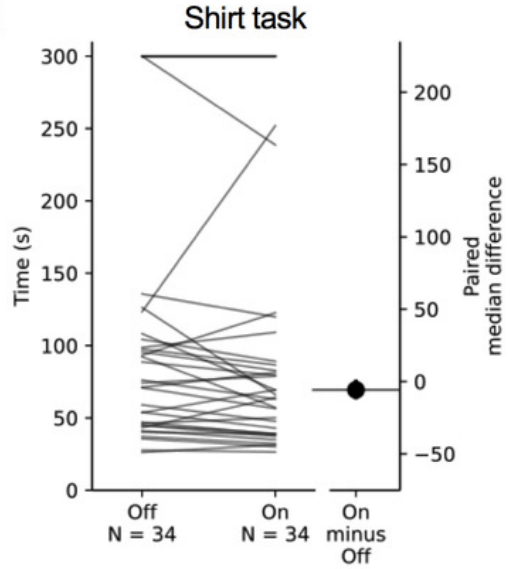

